NBER WORKING PAPER SERIES

\title{
THE IMPACTS OF REDUCED ACCESS TO ABORTION AND FAMILY PLANNING SERVICES ON ABORTION, BIRTHS, AND CONTRACEPTIVE PURCHASES
}

\author{
Stefanie Fischer \\ Heather Royer \\ Corey White \\ Working Paper 23634 \\ http://www.nber.org/papers/w23634 \\ NATIONAL BUREAU OF ECONOMIC RESEARCH \\ 1050 Massachusetts Avenue \\ Cambridge, MA 02138
}

July 2017, Revised December 2017

Previously circulated as "The Impacts of Reduced Access to Abortion and Family Planning Services: Evidence from Texas." We thank representatives from Fund Texas Choice and Jaclyn Bays from Women's Health and Family Planning Association of Texas for providing data. This paper has benefited from helpful comments from Martha Bailey, Tom Chang, Chloe East, Mireille Jacobson, Caitlin Myers, Analisa Packham, Maya Rossin-Slater and Jenna Stearns. We also thank participants at the following conferences: IZA Workshop on Gender and Family Economics, Society of Labor Economics Annual Meetings, Southern California Conference for Applied Microeconomics, CSWEP Session on Family and Gender at WEAI Annual Conference, International Health Economics Association Biennial World Congress, as well as UCSB Labor Lunch Seminar participants and seminar participants at Cal Poly SLO and San Diego State. Certain calculations in this paper are based on data from the Nielsen Company (U.S.), LLC and marketing databases provided by the Kilts Center for Marketing Data Center at The University of Chicago Booth School of Business. The views expressed herein are those of the authors and do not necessarily reflect the views of the National Bureau of Economic Research.

NBER working papers are circulated for discussion and comment purposes. They have not been peer-reviewed or been subject to the review by the NBER Board of Directors that accompanies official NBER publications.

(C) 2017 by Stefanie Fischer, Heather Royer, and Corey White. All rights reserved. Short sections of text, not to exceed two paragraphs, may be quoted without explicit permission provided that full credit, including $\odot$ notice, is given to the source. 
The Impacts of Reduced Access to Abortion and Family Planning Services on Abortion, Births, and Contraceptive Purchases

Stefanie Fischer, Heather Royer, and Corey White

NBER Working Paper No. 23634

July 2017, Revised December 2017

JEL No. I18,I38,J08,J13,J18

\section{ABSTRACT}

Between 2011 and 2014, Texas enacted three pieces of legislation that significantly reduced funding for family planning services and increased restrictions on abortion clinic operations. Together this legislation creates cross-county variation in access to abortion and family planning services, which we leverage to understand the impact of family planning and abortion clinic access on abortions, births, and contraceptive purchases. In response to these policies, abortions to Texas residents fell $20.5 \%$ and births rose $2.6 \%$ in counties that no longer had an abortion provider within 50 miles. Changes in the family planning market induced a $1.5 \%$ increase in births for counties that no longer had a publicly funded family planning clinic within 25 miles. Meanwhile, responses of retail purchases of condoms and emergency contraceptives to both abortion and family planning service changes were minimal.

Stefanie Fischer

Department of Economics

Orfalea College of Business

Cal Poly State University

1 Grand Avenue

San Luis Obispo, CA 93407

sjfische@calpoly.edu

Heather Royer

Department of Economics

University of California, Santa Barbara

2127 North Hall

Santa Barbara, CA 93106

and NBER

royer@econ.ucsb.edu
Corey White

Department of Economics

Orfalea College of Business

Cal Poly State University

1 Grand Avenue

San Luis Obispo, CA 93407

cwhite46@calpoly.edu

An online appendix is available at http://www.nber.org/data-appendix/w23634 


\section{Introduction}

Access to abortion and family planning services has declined precipitously over the past decade. Between 2008 and 2014, the number of facilities providing abortions in the United States fell 6.8\%, continuing a long decline since the early 1980s. In some states, including Texas, this drop has been even more dramatic: the number of abortion-providing clinics shrunk by at least $25 \%$ in 10 states over the 2008 to 2014 period. (Jones and Jerman, 2014, 2017). ${ }^{1}$ Coinciding with this, the abortion rate is at its lowest level since the adoption of Roe v. Wade. ${ }^{2}$

In parallel, the funding of family planning services, which primarily include the dispensary of contraceptives, pregnancy testing, testing of sexually-transmitted diseases, primary care, cancer screenings, and preconception and prenatal care, has similarly decreased (Zolna and Frost, 2016). Per-capita funding levels of Title $\mathrm{X}$, the federal program devoted solely to the provision of family planning services and targeted to low-income women, hit their peak in 2010 and have fallen subsequently. ${ }^{3}$ At its apex of funding, one in four women (and nearly half of poor women) who received contraceptive services did so at a publicly-funded clinic. ${ }^{4}$ In light of the current health care debate, funding cuts to family planning services, including Title $\mathrm{X}$, are likely to continue. Earlier this year, President Trump signed legislation allowing states to withhold Title X funds from family planning clinics that are affiliated with abortion providers. ${ }^{5}$

In this study, we exploit three recent policy changes in Texas to separately understand the effects of reductions in access to abortion and family planning services. Over the 2011 to 2014 period, the Texas legislature implemented legislation that both limited the ability of non-abortion family planning providers to receive government funding and placed more stringent requirements on the operation of abortion clinics. In the aftermath of these policies, over half of abortion clinics closed by 2015, family planning providers experienced funding cuts of $66 \%$ and one-quarter

\footnotetext{
${ }^{1}$ Note, while the change in Texas is large, it is not an outlier. There are seven states with at least as large a decline in abortion-providing clinics over this time period.

${ }^{2}$ See http://www.latimes.com/nation/la-na-abortion-rate-2017-story.html.

${ }^{3}$ See https://www.hhs.gov/opa/title-x-family-planning/about-title-X-grants/funding-history/index.html. Abortion services are less widely-covered by family planning clinics.

${ }^{4}$ Source: https://www.guttmacher.org/fact-sheet/publicly-funded-family-planning-services-united-states.

${ }^{5}$ Title $\mathrm{X}$ funding has never been available for abortion services.
} 
of publicly-funded family planning clinics closed (White et al., 2015). The first two pieces of legislation concerned family planning funding and the last impacted abortion clinics.

As access to these services may affect fertility decisions on multiple margins, we focus on three sets of outcomes to better understand how they affect fertility behavior: abortions, births, and contraceptive purchases. Our analysis leverages spatial and temporal variation in changes to access to reproductive services across counties in Texas using a difference-in-difference design with county fixed effects. Using data on the location of abortion providers and publicly-funded family planning clinics over time, we operationalize the changes in access by focusing on changes in distance to the nearest abortion or publicly-funded family planning provider. We define a publicly-funded family planning clinic as one that receives state or federal funding. For abortion providers, our measure of access exploits closures whereas for family planning clinics, it leverages both closures and changes in the source of funding (e.g., from public funding to non-public funding). Overall, due to the reduced funding, the number of family planning clinics fell and, for many of those that remained open, so did their ability to serve their customer base. As the impacts of distance are unlikely to be linear, our measures of access are more dichotomous - whether or not there is an abortion or family planning clinic within a pre-specified driving distance. For abortion access, much of the action operates on whether or not there is an abortion provider within 50 miles. For family planning, not surprisingly, the most impactful distance is shorter - 25 miles. In 2015, 24\% of the Texas population had no abortion clinic within 50 miles and $11 \%$ had no publicly-funded family planning clinic closer than 25 miles.

How might the reductions in abortion and family planning access impact fertility outcomes such as abortions and births? A priori, the effects are ambiguous. Reduced access to abortion clinics could cause a woman to have a child when she otherwise would not have, leading to fewer abortions and an increase in births. Alternatively, forward-looking individuals may practice safer sex or abstain, resulting in fewer abortions and potentially lower birth rates. ${ }^{6}$ If the increased distance is not prohibitive, one might expect no alteration in either births or abortions. Similarly, the

\footnotetext{
${ }^{6}$ This is the basic finding of Kane and Staiger (1996) for teenagers in the response to the closing of abortion clinics and declines in Medicaid funding.
} 
effect of reduced access to family planning services may also be ambiguous. Reduced access may lessen the frequency of contraceptive use, such as IUDs and condoms, which are often dispensed for free or reduced cost at such clinics. As a result, the incidence of unintended pregnancy may increase, possibly leading to either increased abortions, increased births, or both. The impact of family planning services may also operate through sexual education and family planning practice knowledge. In this case, it would be reasonable to expect fertility rates to increase with more restricted access to family planning services.

Several features make Texas an interesting and useful case study. First, the policies examined here are reflective of those currently on the the policy agenda nationwide. Second, estimated effects in Texas are likely more informative about the effects of nationwide policy changes compared to the analysis of other states. Because of Texas' size, travel across state lines to other states is less feasible for most residents. Third, unlike in most other states, by law, family planning services are administered separately from abortion services, and thus, we can separately estimate effects of changes in access to abortion and family planning services. ${ }^{7}$ Fourth, Texas maintains a consistent and high-quality set of data on abortions by county and age. National abortion data are limited and sparse and the quality (i.e., completeness) of state-level data varies significantly (Jacobson and Royer, 2011).

At first glance, the effects of this legislation look dramatic as seen in Figure 1. This figure displays the time-series patterns of births in Texas alongside a synthetic control for Texas. The three vertical bars represent the three pieces of legislation we exploit - first, Department of State Health Services (DSHS) cuts in 2011 reduced funding for family planning clinics by 67\%; second, the Women's Health Program (WHP) effectively eliminated Medicaid fee-for-service reimbursement of family planning services for Planned Parenthood in early 2013; and third, later that year, House Bill 2 (HB2) imposed significant regulations on the operation of abortion providers. The fertility rates for Texas and its synthetic control begin to diverge slightly after the enactment of the DSHS

\footnotetext{
${ }^{7}$ The other states with similar policies include Arizona, Arkansas, Colorado, Indiana, Ohio, and Wisconsin. Source: https://www.guttmacher.org/state-policy/explore/state-family-planning-funding-restrictions.
} 
cuts and the pace of separation accelerates with the WHP legislation and HB2. ${ }^{8}$

Exploiting the quasi-experimental variation in abortion access in Texas, having no abortion provider within 50 miles in Texas reduced in-state abortion rates by $20 \%$. Of course, a focus on in-state abortions may not capture the total effect on abortions because women may travel outside of Texas to receive an abortion or may self-administer an abortion. ${ }^{9}$ For this reason, the impact of the reduction in abortion access on births, a 3\% increase, is more informative of the total effect on fertility-related behaviors. Not surprisingly, given the myriad of available contraceptive technologies and the larger network of family planning clinics, the effect of family-planning closures on births, as measured by whether or not there is a clinic within 25 miles, is more muted. Overall, not having a clinic within 25 miles increased births by $1 \%$. The effects are heterogenous across different demographic groups, with larger effects experienced among higher parity, Hispanic, older and married mothers.

While it is standard in the abortion and family-planning literature to focus on the outcomes of abortions and births, such analyses miss impacts on precautionary behaviors (e.g., contraceptive use). This is mainly due to data limitations rather than a lack of interest. Earlier papers by Akerlof et al. (1996) and Kane and Staiger (1996) develop theoretical models showing that fertilityimpacting policies could influence the use of contraceptives. Using Nielsen Retail Scanner data on a large sample of retailers that contains the price and quantity of nearly every item purchased in participating outlets (mostly grocery stores and drug stores), we find that diminished access to family planning services increased contraceptive expenditures in counties without a family planning clinic within 25 miles. Results are less clear in regards to the effects of reduced abortion

\footnotetext{
${ }^{8}$ The DSHS cuts impact births with a delay. In our later analysis, the effects of the changes in family planning services do act with a 1-year delay. There are two possible explanations for this delay. First, given the length of time between conception and birth of 40 weeks, there is a delay between the policy's enactment and the observed effect of the policy. Second, one of the most common services of family planning providers is the insertion of intrauterine birth control devices (IUDs), which have lifespans of several years. Thus, while a reduced ability to provide IUDs will affect the flow of women receiving IUDs, the effect on the stock of women with IUDs, the relevant at-risk group, takes longer to manifest.

${ }^{9}$ The Texas Policy Evaluation Project at The University of Texas at Austin estimates that at least 100,000 women in Texas have attempted a self-induced abortion. This statistic is likely higher in Texas than in other states due to the close proximity of Texas with Mexico where misoprostol, an abortion-inducing drug, is available at pharmacies without a prescription. See http://liberalarts.utexas.edu/txpep/news/article.php?id=10043.
} 
access.

We provide several specification checks to insure that we are identifying the effect of access rather than potentially coinciding factors. Our exploited quasi-experimental variation occurs on the cusp of the Great Recession when fertility rates were falling. To understand whether our results are biased by these trends, we limit the time period of our data (e.g., examination of data 2010 and later as opposed to 2006 and later) and include Health Service Region trends and end up with similar results. We also attempt to predict changes in clinic access using pre-policy changes in fertility rates and find no statistically significant relationship, further suggesting that differential pre-trends in the outcome are unlikely biasing results. ${ }^{10}$ We re-run our results excluding border counties, whose access to abortion and family planning services may be dictated more by nearby states or Mexico, and our results are consistent. However, one caveat to our work is that we use cross-county and cross-time variation within Texas, effectively contrasting more affected with less affected counties in Texas. This contrast, of course, will miss the overall effect of the legislative changes on reproductive services in Texas. To ascertain how this affects the conclusions of our analysis, we compare the time trends in Texas with similar states as shown earlier in Figure 1. While one might argue that such analysis is not as credible as those produced from our main identification approach, the estimated effects on births are quite similar - a $2.6 \%$ increase.

This study complements the extensive previous work on family planning and abortion services in three important ways. First, we focus on a substantial and significant contraction in family planning and abortion services. Much of the existing literature focuses on early expansions in family planning and abortion access (e.g., Roe v. Wade and the adoption of the birth control pill). ${ }^{11}$ Exceptions include the implementation of parental consent and notification laws (Blank et al., 1996; Joyce and Kaestner, 1996; Levine, 2001; Averett et al., 2002; Levine, 2003; Joyce et al., 2006;

\footnotetext{
${ }^{10}$ This indirect test for parallel trends in the pre-policy period is similar to a procedure used in Lu and Slusky (2017).

${ }^{11}$ For example, many studies have examined the expansion of oral contraceptives and show that it led to delayed childbearing, reduced fertility, increased career investment for women, and better child outcomes (Goldin and Katz, 2002; Bailey, 2006; Kearney and Levine, 2009; Bailey, 2010, 2012; Ananat and Hungerman, 2012; Bailey, 2013). Using more recent variation in contraceptives, Gross et al. (2014) show that expanding access to emergency contraceptives has little effect on birth or abortion rates, while Lindo and Packham (2015) conclude that expanded access to long-acting reversible contraceptives through the Colorado's Family Planning Initiative reduced teenage fertility rates.
} 
Guldi, 2008; Colman et al., 2013; Sabia and Anderson, 2016) and waiting periods (Bitler and Zavodny, 2001), but these policies only affect teenagers. Given the current policy environment and the fact that contractions in coverage may incur different impacts than expansions in coverage, our study is relevant for understanding the effects of policies under debate today. Second, we focus on contemporary variation in access (i.e., changes within the last decade). During the 2000's, contraceptive technologies (e.g., IUDs, hormonal patch, vaginal ring, and female condom) improved in terms of their effectiveness and safety. ${ }^{12}$ Moreover, over time, female labor force participation has markedly increased, making a woman's decision to bear a child more complicated. Thus, fertilityrelated policies today might affect behaviors differently from the past. Third, the combination of the distinct and separate quasi-experimental variation in abortion clinic access and family planning services (the correlation in the variation is 0.14) and the legislative environment in Texas (i.e., family planning services providers do not provide abortion services), we can isolate the impact of changes in family planning services from changes to abortion services.

Most related to this paper are Grossman et al. (2017) and two concurrent working papers, Lu and Slusky (2017) and Cunningham et al. (2017), which all leverage the recent restrictions in reproductive clinic access in Texas. Using a unique data source on the locations of a large family planning clinic provider, Lu and Slusky (2017) examine the effect of clinic closures within that network on births through 2013 (prior to the major change in access to abortion). However, such analyses miss changes to the market of abortion services and other family planning clinics in Texas. In 2011, the largest Texas provider of family planning services was Planned Parenthood, which provided services to $40 \%$ of family planning clients. But two-thirds of the clinics that closed were not Planned Parenthood Clinics. ${ }^{13}$ In a short research letter in The Journal of the American Medical Association, Grossman et al. (2017) correlate county-level changes in the distance to an abortion provider from 2012 to 2014 with county-level changes in abortion rates. Likewise Cunningham et al. (2017) focus on abortion clinic closures and their effects on abortion in more

\footnotetext{
${ }^{12} \mathrm{See}$ http://www.ourbodiesourselves.org/health-info/a-brief-history-of-birth-control/.

${ }^{13}$ Source: https://www.washingtonpost.com/posteverything/wp/2017/02/07/defunding-planned-parenthood-was-adisaster-in-texas-congress-shouldnt-do-it-nationally/.
} 
expanded regression analysis controlling for potential confounding factors. Additionally, two other papers look at more specific aspects of the Texas legislative changes. Packham (2016) studies the behavioral response of teenagers to the 2011 family planning funding cuts and Stevenson et al. (2016) quantify the effect of the ineligibility of Planned Parenthood for public funding in 2013 on the dispensary of contraceptives at family planning clinics.

We take a more comprehensive approach to understanding the effect of the Texas legislative changes. First, rather than focusing on the abortion clinic access or family planning clinic access exclusively, we leverage independent variation in both access to abortion and family planning clinics to separately identify their effects on reproductive behavior. As the two types of clinics provide complementary types of services, they are both important to consider together. Second, we study a broader set of fertility outcomes in an attempt to gain a better understanding of the different ways in which Texas women are changing their fertility behavior. These include abortions, births and over-the-counter contraceptive purchases. Such a focus is essential since the Texas legislation could affect reproductive decisions and outcomes on several margins.

\section{Background}

In Subsection 2.1 we describe the policy setting in the U.S. and Texas. Subsection 2.2 includes a detailed discussion of the three pieces of Texas legislation leveraged in this study.

\subsection{Policy Setting}

In 2014 , there were $1,795,160$ women in need of free or subsidized reproductive care in Texas. The Guttmacher Institute characterizes a woman in need if she is sexually active, is able to conceive, wishes not to become pregnant, and is an adult with a family income below 250 percent of the federal poverty level or is younger than 20 years of age (regardless of income). Publicly-funded family planning clinics serve these women and they encompass a diverse set of health providers including public health departments, federally qualified health centers, Planned Parenthood affiliates, 
hospital outpatient clinics, and other independent non-profit health centers. ${ }^{14}$ Services provided by publicly-funded clinics include free or subsidized contraceptives, screenings for sexually transmitted infections (STIs), Pap tests, vaccination for human papilloma virus (HPV), other key preventive care services, and sexual education.

Publicly-funded clinics may receive a variety of federal and state grants. Title $\mathrm{X}$, one of the main funding sources for family planning clinics, is a federal program dedicated to family planning. ${ }^{15}$ Congress introduced Title X in 1970 as part of the Public Health Service Act. The goal of this legislation was to make family planning services available to women who wanted them but were unable to afford them. Today, Title X clinics still play a critical role in ensuring all women have access to family planning services. It remains the only federally funded program dedicated solely to providing reproductive care to low income and uninsured individuals. Receipt of Title $\mathrm{X}$ funds is also tied to other federal programs. Clinics receiving Title $\mathrm{X}$ funds are eligible for the federal 340B Drug Pricing Program, which provides discounts on pharmaceuticals (including contraceptives) of up to 50\%. Clinics receiving Title X funds are exempt from state-level parental consent laws (including Texas) that require teenage women to gain parental consent before obtaining prescription contraceptives. ${ }^{16}$

Despite this large demand for subsidized reproductive services, public funding for these clinics remains controversial among policymakers and the general public. Those that seek to limit public funding for family planning clinics often view these clinics as closely tied to abortion clinics. Federal law does permit publicly-funded family planning clinics to provide abortions, but it is unlawful for federal dollars to fund such procedures. Certain states including Texas, however, go a step further and disallow family planning clinics that receive any public funding from providing abortions. This law has been in effect in Texas since 2003. Proponents of the law believe that in

\footnotetext{
${ }^{14}$ There also exists in the U.S. a small number of non-profit family planning clinics that are funded exclusively by private contributions and receive no tax dollars, though in Texas these are quite rare.

${ }^{15}$ Publicly-funded family planning clinics are also funded by Medicaid (the largest source of funding), Title V (maternal and child health), and Title XX (social services).

${ }^{16}$ Note that laws requiring parental consent for prescription contraceptives are distinct from those that require parental consent for abortion; only Texas and Utah have laws requiring parental consent for prescription contraceptives.
} 
the absence of such restrictions, abortion services are indirectly funded as clinics can use public funds for eligible services, thereby freeing up non-public funds for abortions.

Because of these federal and state laws, in Texas there are two distinct types of clinics that are relevant to our study: stand-alone abortion clinics that exclusively provide abortion services and are privately funded, and publicly-funded family planning clinics which provide contraceptive care and other services, but not abortions. ${ }^{17}$

\subsection{Legislative Background}

We leverage three state-level reproductive policies that create large unanticipated shocks to the supply of abortion and non-abortion family planning services in Texas: (1) the 2011 cut to the Department of State Health Services (DSHS) for publicly-funded family planning services, (2) the 2011 change in the Women's Health Program which was rolled out in 2013 and disallowed certain clinics from receiving Medicaid reimbursements, and (3) House Bill 2 which took effect in 2013 and greatly reduced access to abortion clinics.

\subsubsection{Cuts to DSHS Funding}

In 2011, the Texas government enacted two main pieces of legislation which drastically cut funds to family planning clinics in the state, and in particular reduced funding to Planned Parenthood affiliates. The first funding cut reduced the DSHS budget for family planning services. Previously, DSHS funded clinics through federal and state grants including Title V (maternal and child health), Title X (family planning), and Title XX (social services).

The budget cut to DSHS reduced funding by about $67 \%$ - a cut from $\$ 111$ million per biennium to $\$ 37.9$ million for the 2012 - 2013 biennium budget. Importantly, this piece of legislation also reallocated the remaining funds according to a newly-implemented tiered system which granted

\footnotetext{
${ }^{17}$ Woman may also obtain abortions from a hospital or a general practitioner, but in Texas in 2012 - according to a report by the Texas Department of Social and Health Services - only 0.3 percent of all abortions took place in these types of facilities, where most of them involved an extenuating circumstance (i.e., ectopic pregnancy). By and large, Texas women obtain these services in stand-alone clinics.
} 
funding priority to clinics providing comprehensive primary care over those whose emphasis was on family planning. Planned Parenthood clinics were lowest in funding priority.

These reductions in funding greatly reduced access to family planning clinics. Of the roughly 200,000 women receiving care through these programs, $40 \%$ received services from Planned Parenthood and other clinics specializing in family planning (White et al., 2015). According to White et al. (2015) during 2012, 25\% of clinics shut down, and many of the ones that remained open were forced to reduce hours of operation and/or downsize staff. Of the remaining clinics, on average, they only served $54 \%$ of the patients that they served in the pre-period. Moreover, due to the funding cuts, in many cases women were now required to pay fees for services and prescriptions that were once free of charge.

Title $\mathrm{X}$ funds are a particularly important funding source for family planning, and by reallocating Title $\mathrm{X}$ funds according to the new priority-based funding scheme, many clinics whose emphasis was on family planning ceased to receive Title $\mathrm{X}$ funds beginning in 2011. Because of how the DSHS was allocating these funds, the federal government ceased awarding the sole Title X grant for the state of Texas to DSHS, and instead awarded it to an organization not run by the state of Texas: the Women's Health and Family Planning Association of Texas (WHFPT). WHFPT did not have to abide by the state's priority-based funding scheme, and were able to restore Title X funds to some clinics specializing in family planning.

\subsubsection{Medicaid Fee-for-Service Family Planning Program}

In 2011 the Texas government also passed legislation that excluded family planning clinics that were affiliated with abortion providers (e.g., Planned Parenthood affiliates) from receiving reimbursements through the Women's Health Program (WHP). This law took effect in 2013.

The WHP was a fee-for-service family planning program with the goal of subsidizing family planning services for low income women. Through this program women could obtain, either for free or at a subsidized rate, contraceptives, cancer screenings, STI testing and treatments, pregnancy tests, and pap tests and pelvic exams. From 2007 to 2011, Texas operated this program 
through a Medicaid waiver program meaning that it was almost entirely funded by federal dollars; approximately $\$ 30$ million per year comprising 90\% of the annual budget for WHP (White et al., 2015)..$^{18}$

However, in 2011 when the Texas government passed this legislation, the federal government terminated their contribution stating that the legislation violated federal law by discriminating against qualified federal providers. The state of Texas responded by replacing the WHP with a state-funded program called the Texas Women's Health Program (TWHP), which was implemented on January 1, 2013. This program was identical to the previous federally funded program but excluded all clinics in a network affiliated with abortion providers and was funded by state dollars.

\subsubsection{House Bill 2}

On July 18, 2013 Texas House Bill 2 (HB2) was signed into law. In contrast to the previous two pieces of legislation that reduced funding for non-abortion family planning clinics, HB2 was aimed more directly at abortion providers. Broadly, the bill imposed expensive and difficult-to-implement requirements on abortion facilities. Such bills are often know as Targeted Regulation of Abortion Provider (TRAP) laws. The bill required the following: (1) physicians administering abortions must have admitting privileges at a hospital within 30 miles of the abortion clinic, (2) abortions after 20 weeks post-fertilization are prohibited, unless there is severe fetal abnormality or risk of irreversible physical impairment of a major bodily function (not including psychological) to the mother, (3) in accordance with Food and Drug Administration regulation, women must visit the doctor for each of the two doses of the abortion pill and, after taking the pill, the patient must be seen in a follow-up appointment within 14 days, ${ }^{19}$ and (4) all abortions must be performed in a clinic that meets the requirements of an ambulatory surgical center (Texas 83rd State Legislature, 2013; Fund Texas Choice, 2014).

\footnotetext{
${ }^{18}$ Medicaid is a health care safety net program in the United States typically funded jointly by federal and state governments.

${ }^{19}$ This is in addition to the existing 24 hour waiting law that requires women who are within 100 miles of a clinic to wait 24 hours between the initial visit and the actual abortion including those seeking the pill.
} 
The first three provisions of the bill went into effect on November 1, 2013, causing the first wave of abortion clinic closures. The fourth provision of HB2, which required all abortion facilities to meet the requirements of ambulatory surgical centers, was enforced in October of 2014. Converting a clinic to meet these standards is costly both financially and in time as there is a detailed licensing process, and clinics have to meet physical requirements such as certain room dimensions and corridor widths. This regulation caused several additional clinics to close, and by 2015, over half of the abortion clinics from the pre-HB2 period were no longer in operation.

\section{Data}

\subsection{Abortion and Family-Planning Provider Data}

\subsubsection{Abortion Provider Data}

The main data source for clinic locations and dates of operation are license files from the Texas DSHS that provide information on all abortion clinics in the state for the years 2006-2015. These data include exact license dates for each clinic (both start and expiration dates) as well as each clinic's address. ${ }^{20}$

We crosscheck the DSHS data with information on abortion clinic closures from a Texas nonprofit, Fund Texas Choice. The mission of Fund Texas Choice is to help pay for abortion travelrelated expenses, particularly for low-income, teen, and rural Texans. As such, they have more upto-date information on clinic closures, particulary during the roll-out of HB2 in 2013-2014. Fund Texas Choice periodically calls all clinics in Texas and border states to determine which clinics are providing abortions and keeps an ongoing record of clinic closures. In addition to validating the DSHS abortion data, we have appended the DSHS license data with data from Fund Texas

\footnotetext{
${ }^{20}$ We determine the exact latitude/longitude coordinates of each clinic using a geocoding service provided by Texas A\&M University: http://geoservices.tamu.edu/Services/Geocode/.
} 
Choice on the location and operation dates of clinics in neighboring states. ${ }^{21}$ Finally, to further reduce concerns about measurement error in closure dates, we contacted each of the clinics that we observe as being operational in September 2016 to verify that they are still providing abortions.

\subsubsection{Family Planning Provider Data}

Family planning centers include a diverse set of providers. To maintain consistency over time, we define publicly-funding family planning clinics as those clinics receiving state or federal funding. Data on family planning clinic funding come from three sources. The first file comes from DSHS and indicates in each year the clinics in Texas that received family planning funding through this agency. The second dataset comes from WHFPT, the agency that took over the Title X grant for the state in 2013. This data indicates in each year from 2013 to 2015 the clinics that received Title $\mathrm{X}$ funds. This second source is necessary as the data from DSHS include only clinics that were funded through DSHS-administered programs, and as Title X was no longer overseen by DSHS, would exclude Title $\mathrm{X}$ funding. Combined, these first two data sources represent a complete list of clinics in Texas receiving public funds for each year 2006-2015, including information on each clinic's address.

We supplement these two data sources with data on publicly-funded family planning clinics in nearby states. For the year 2010, the Guttmacher Institute collected data on the number of publicly-funded family planning clinics per county for each state. We use the Guttmacher data to account for the possibility that women near state borders may be traveling out of state to seek family planning services. Unfortunately, these data only cover a cross-section and thus, we cannot account for changes in the number of publicly-funded family planning clinics outside of Texas over time. For the purposes of our regression analyses, if we observe a positive number of clinics in any non-Texas county in 2010, we assume that there was an operational clinic in all years of our sample located at the population-weighted county centroid. In practice, as we describe in

\footnotetext{
${ }^{21}$ Using the Fund Texas Choice data, we amended 13 of the closure dates provided by DSHS. These were typically minor discrepancies in dates (there were no discrepancies in which clinics closed), and in all cases the DSHS closure dates were later than those from Fund Texas Choice, suggesting that these DSHS licensure dates lagged behind actual closure.
} 
further detail below, our measure of access to family planning is an indicator for whether there is a publicly-funded clinic within a short distance (i.e., 25 miles), and as such accounting for family planning services in nearby states has very little influence. Most importantly, when we exclude border counties (i.e., those areas which may have a family planning clinic within 25 miles but that clinic is located in a different state) from the analysis, our estimates are qualitatively similar. ${ }^{22}$

\subsubsection{Measuring Abortion and Family Planning Access}

Our primary measure of access to abortion is the driving distance from each county to the nearest clinic providing abortions. To construct this measure, information on the location and dates of operation for all clinics offering abortions in both Texas and neighboring states is necessary. We calculate the straight-line distance between the population-weighted county centroid for each county in Texas and the geographical coordinates of each clinic's exact address. For all clinics that are among the five closest in terms of straight-line distance in any time period, the driving distance is calculated, and the minimum is chosen as the county's closest abortion clinic. ${ }^{23}$

Since the effects of distance are unlikely to be linear, we construct three different binary measures of abortion clinic access: no clinic within 25 miles, no clinic within 50 miles, and no clinic within 100 miles. To provide context, in 2015 the share of the Texas population that lived in an area with no abortion clinic within 25 miles, 50 miles and 100 miles was 40\%, 26\%, and 13\% respectively. In our regression analysis, the across time, within-county variation in abortion clinic access then exploits clinic closures. ${ }^{24}$

For family planning services, our measure of access is slightly different. As family planning

\footnotetext{
${ }^{22}$ See Table A1.

${ }^{23}$ Driving distance is calculated using the Stata program Georoute (Weber et al., 2016). We first calculate the straight-line distance for each of the closest five clinics to avoid using the driving distance API for thousands of coordinate pairs. In most cases, the closest clinic in terms of straight-line distance is also the closest clinic in terms of driving distance. Because Texas does not have significant geographical features (e.g., large mountain ranges), the straight-line distance is a very good proxy for the driving distance. Ultimately, our results are not sensitive to the use of either straight-line distance or driving distance (except in interpretation, as driving distances are longer).

${ }^{24}$ In principal, our measure of access will vary in response to clinic opening too, but the majority of clinic openings over our period occur in the beginning of the sample frame and our estimates are not sensitive to the exclusion of these earlier years. Furthermore, clinic opening that occur at the end of the sample frame were in response to HB2 (i.e., clinic re-openings, or clinics that opened to replace a closed clinic).
} 
clinics are more prevalent than abortion clinics, we leverage shorter changes to distance. We use indicators of no publicly-funded clinic within 10 miles (23\% of the population in 2015) and no publicly-funded clinic within 25 miles (13\% of the population in 2015). ${ }^{25}$ The family planning clinic access measure captures changes to the funding status of the clinic and not necessarily just clinic closures. As such, this access variable captures changes along both the intensive and extensive margins. We view this as a preferable measure as the funding cuts to family planning clinics affected the ability of many clinics to provide family planning services, while not necessarily resulting in a closure. For instance, if a county in a given month-year no longer has a publicly-funded family planning clinic within 25 miles, then it could be that the clinic closed or that it remained open and now operates on restricted hours, with reduced staff, and/or has substituted toward relatively lower cost procedures and drugs. Furthermore, the loss of Title X funding makes the clinic ineligible for the 340B Drug Discount Program which provides large subsidies for expensive contraceptives such as long acting reversible contraceptives (LARCs) and removes the clinic's exemption from the Texas state parental involvement law for prescription contraceptives. Whether the clinic closed or remained open without public funding, access has been restricted in either scenario.

The variation in access to abortion that we utilize is summarized in Figure 2, which visually displays the change in our measure of abortion access for each county in Texas across the last six years of our sample. Starting in 2013, consistent with the timing of the Texas policies, we see considerable changes in the distances to the nearest abortion provider with many counties experiencing a change of 100 miles or more.

Similarly, the variation in access to publicly-funded family planning is displayed in Figure 3 and demonstrates the change in our measure of family planning access within each county in Texas across the last six years of our sample. This map reinforces that the changes in distance to family

\footnotetext{
${ }^{25} \mathrm{We}$ focus on the 25 mile measure for family planning as there is high potential for measurement error with the 10 mile measure given that we are only able to observe county of residence. Because county centroids are populationweighted we are essentially measuring the distance between a county's metropolitan center and the address of the nearest clinic; as such, the 10-mile measure is intended to reflect the absence of publicly-funded family planning clinics from a county's metropolitan center.
} 
planning providers we exploit is shorter. It also reveals how geographically disperse the variation in access is relative to the abortion access. Contrasting Figure 2 and Figure 3, it is not surprising how little the variation in abortion access and family planning access are correlated.

\subsection{Other Controls}

To mitigate worries about confounding factors such as economic and population change, we collected county-by-year unemployment rates and per-capita income from the Bureau of Labor Statistics's Local Area Unemployment Statistics and the Regional Economic Information System. We also use age-specific population counts from the Census Bureau and race/ethnicity-specific population counts from the CDC Wonder system. Note that all these control variables are measured at the county-by-year level, so we interpolate across months within the year in our county-by-month level regressions to avoid large jumps at the start of the year.

\subsection{Outcome Data}

\subsubsection{Abortion Data}

We obtain data on all legal abortions performed in the state of Texas by age and county of patient's residence for the years 2006-2014 from Texas DSHS. This data allows us to test whether changes in access to abortion or family planning have led to changes in abortions performed within Texas; this data does not allow us test for a total net change in abortions performed if women travel out of state. Data on within-Texas abortion rates (per 1,000 women in the corresponding age group) are described in Table 1. The overall abortion rate is nearly 13; slightly higher than the 2013 national average of 12.5 (Jatlaoui, 2016). The abortion rate is highest among 20-29 year old women.

To better understand the degree to which women travel to other states for abortion services, we also collect abortion counts in this same time period for each of the states near Texas, including all border states - Arkansas, Colorado, Kansas, Louisiana, New Mexico, and Oklahoma - from each state's health department. These data are more limited than the Texas data in the sense that we can 
calculate the number of abortions to non-resident women in these outlying states but we do not know from which state or county they come from. Nevertheless, we can provide some descriptive evidence of travel behavior using cross-time and cross-state variation.

\subsubsection{Natality Data}

Birth data come from the restricted version of the National Vital Statistics System (NVSS) natality files. These files contain information on all U.S. births including information on the county of mother's residence, the year and month of birth, and mother characteristics (e.g., age, education, ethnicity, marital status, and parity). We utilize data on all births of mothers residing in Texas occurring between 2006-2015 (3,663,482 births).

The timing of access to abortion and family planning relative to the timing of births is an important consideration. Specifically, births should be matched to abortion and family planning access at the time when access to these services is most relevant to fertility decisions. As such, we match births to abortion clinic access at the 13th week of gestation (i.e., the end of the first trimester), and to family planning clinic access at the time of conception. ${ }^{26}$ For abortion, matching at the time of conception would be inappropriate as there is not yet any knowledge of pregnancy; matching at any point beyond the 20th week of gestation would be inappropriate as Texas law prohibits abortion after the 20th week. The end of the first trimester represents a point at which the decision to receive an abortion is still actionable. For family planning, matching at any time beyond conception would be inappropriate if one believes that the primary purpose of access to family planning is preventing unintended pregnancy. Because access to family planning prior to the time of conception may be even more relevant, we explore the extent to which lags in access to

\footnotetext{
${ }^{26}$ Matching births to abortion access at the 13th week of gestation requires first identifying the month in which each child is at their 13th week of gestation; this is done using information on the month of each birth and the number of weeks in gestation. The number of weeks in gestation (converted to months by multiplying by $7 / 30.5$ ) is subtracted from the birth month, and 13 weeks (converted to months) is added. The function used is as follows: Week13= round $(($ BirthMonth+0.5) $-($ WeeksGestation*7/30.5) $+(13 * 7 / 30.5))$. Note that 0.5 is added to the birth month to represent the middle of the month rather than the start. Next, the data on births (where the year and month represent the 13th week) are merged with our measures of access. At this point, both abortion access and family planning access are defined at the 13th week of gestation - to ensure family planning access is defined at the time of conception, our measure of access to family planning is lagged by 3 months (approximately 13 weeks). In exploring further lags in access to family planning, we refer to this 3 -month lagged version as $\mathrm{t}=0$ denoting the time of conception.
} 
family planning are important.

Although we have data on births that occur in all months of 2015, the process of assigning births to abortion access at the 13th week of gestation means that a birth occurring in December will most commonly have been in its 13th week of gestation in June or July. As such, we only use data on pregnancies leading to birth through May 2015 since it is highly unlikely that a pregnancy in its 13th week in May 2015 would result in a post-2015 birth.

We utilize other features of these data to explore the heterogeneity of our estimates - in particular, we examine the number of births by age (15-19, 20-29, 30-39, 40-44), by ethnicity (Hispanic, non-Hispanic), by education (high school or less, some college or more), marital status (married, unmarried) and live-birth parity (first, second, third, fourth or more). Summary statistics for these data are provided in Table 1. The overall fertility rate is elevated relative to the 2015 national average of $62.5 .^{27}$

\subsubsection{Contraceptive Purchases}

An earlier literature (Akerlof et al., 1996; Kane and Staiger, 1996) highlights a potential interaction between reproductive policies and contraceptive use. However, testing the effect of reproductive policies on contraceptive use has proven to be challenging - mainly due to limited data. In this paper, we bring to bear new data on contraceptive use from the Nielsen Retail Scanner database. These data cover the years 2006-2014. This large database covers more than 35,000 grocery, drug and mass merchandise retailers across the U.S. and accounts for more than half of the total sales volume in grocery and drug outlets and approximately one third of sales volume for mass merchandise outlets. These data provide weekly sales volumes and prices for nearly every item sold in participating outlets. ${ }^{28}$

There are approximately 2.4 million items included in the data (items are identified by their

\footnotetext{
${ }^{27}$ Source: https://www.cdc.gov/nchs/nvss/births.htm

${ }^{28}$ Exceptions include prescription drugs, for instance. This measure of contraceptive purchases will be an undercount of total contraceptive use as family planning clinics, doctors' offices, and other health care providers dispense contraceptives. However, one of the goals with these data is to understand the degree to which over-the-counter purchases of contraceptive purchases substitute for contraceptives offered by health care providers.
} 
UPC code). Our focus is on contraceptives. Nielsen groups items into approximately 1,100 categories at the finest level, including two categories for contraceptives: "Male Contraceptives" and "Female Contraceptives." The vast majority of products in the "Male Contraceptives" category refer to traditional contraceptives such as condoms. We use expenditures on all products in this category as our primary outcome of interest. ${ }^{29}$ Products in the "Female Contraceptives" category represent a wider range of products including ovulation tests and emergency contraceptives. Because some of the products in this category may be used to improve the likelihood of pregnancy rather than prevent pregnancy (e.g., ovulation tests), we instead focus on the "Male Contraceptives" category. We henceforth refer to "Male Contraceptives" as simply "Contraceptives."

We also use data on all purchases within the broad "Health and Beauty" product grouping. To account for the wide variation in store size, we weight our regressions (which we estimated at the store level) by average store expenditures on all "Health and Beauty" products. Within "Health and Beauty," products are further grouped into 18 sub-categories, one of which contraceptives are a part. As a falsification test, we examine the impacts of access to abortion and family planning on the 17 other sub-categories to which contraceptives do not belong.

Our sample consists of 2,625 stores in Texas that were operating between 2006-2014 and had positive sales for contraceptives in at least one period. ${ }^{30}$ We construct total expenditures for contraceptives in each store at the monthly level. The finest geographical identifier for each store is the county, allowing us to merge these store-level data with our measures of access to abortion and family planning.

\section{Empirical Framework}

We exploit quasi-experimental variation in access to family planning clinics and abortion clinics across counties and over time in Texas to separately identify the causal relationship between ac-

\footnotetext{
${ }^{29}$ Indeed, to the best of our knowledge, all products in the "Male Contraceptives" category are condoms. Note that in the final year of the sample, there were 1,013 such products in this category.

${ }^{30}$ Sixty-five percent of stores operated in all months of the data and eighty percent operated in all but one year.
} 
cess to each type of clinic and the number of abortions, the number of births, and contraceptive purchases. ${ }^{31}$ Essentially, we compare changes in outcomes between areas where clinic access became more restricted to areas that experienced relatively little change. ${ }^{32}$ The general form of our difference-in-difference model is as follows:

$$
Y_{c t}=\beta_{0}+\beta_{1} \operatorname{Access}_{c t}+\beta_{2} X_{c t}+\gamma_{c}+\alpha_{t}+\varepsilon_{c t}
$$

$Y_{c t}$ is the outcome in a given county $c$ and time $t$. In the analysis of abortions, $t$ represents years as the data are at the county-year level; in the analysis of births, $t$ represents year-months as the analysis is at the county-year-month level. Because the abortion and birth data include cells with zero counts, we estimate these models using a Fixed-Effects Poisson Quasi-Maximum Likelihood estimator. This estimator allows for the inclusion of county fixed effects but is free of the common incidental parameters problem often present in other non-linear models (Cameron and Trivedi, 2013). To account for the fact that counties vary widely in size and therefore have a different potential for births and abortions, in all count models the relevant population - i.e., women of childbearing age (15-44) - is included as the exposure variable. ${ }^{33}$

Access $_{c t}$ is either a measure of abortion clinic access or publicly-funded family planning clinic access. As we described in the data section, abortion access is characterized by either (1) no abortion clinic within 25 miles, (2) no abortion clinic within 50 miles, or (3) no abortion clinic within 100 miles. The family planning access is captured via either (1) no publicly-funded clinic within 10 miles or (2) no publicly-funded clinic within 25 miles. In each of our regressions, we only include a single indicator for clinic access (e.g., no clinic within 25 miles) rather than the full set of indicators. This allows for more variation in the access data, and thus, ensures that there is

\footnotetext{
${ }^{31}$ A similar identification strategy is used in the literature that documents the effect of distance or proximity to health care providers on individual outcomes, i.e., Buchmueller et al. (2006).

${ }^{32}$ It is possible that the regions in Texas that we define as relatively unaffected are still affected by these policies to some degree due to, for example, increased congestion at the clinics that remain open. As such, our estimates provide a lower bound of the total effect.

${ }^{33}$ Note, Poisson models are used when the outcome is a count not a rate. However, in this context the potential for exposure is nonconstant across observations. To account for this, we include the exposure variable which enters on the right-hand side of the equation where the parameter estimate is logged and constrained to one. In our age-specific models we use age-specific populations as the exposure variable.
} 
sufficient power to identify the impacts of interest. For example, county A with the closest clinic within 10 miles in 2012 and with the closest clinic with 60 miles in 2013 would lead to variation in both the no abortion clinic within 25 miles and no abortion clinic within 50 miles measure.

As we are interested in understanding the effect of abortion access separate from that of family planning access, in our preferred specifications we control for family planning access (in the case of abortion access regressions) and abortion access (in the case of family planning access regressions). The low correlation of 0.14 between the changes in abortion access and family planning access we exploit enables us to disentangle the effects of each separately. This is also highlighted in Figures 2 and 3, which show that the areas most affected in terms of abortion access do not substantially overlap with the areas most affected in terms of family planning access.

Finally, in Eq. (1), $X_{c t}$ represents a vector of time-varying county-level controls which includes the unemployment rate, per capita income, race/ethnicity-specific populations (Hispanic, White non-Hispanic, Black non-Hispanic, and Other), and female age-specific populations (5-year groups between 15 and 44). ${ }^{34} \gamma_{c}$ and $\alpha_{t}$ are county and time fixed effects, respectively. ${ }^{35} \varepsilon_{c t}$ is the error term and is clustered at the county level. Clustering accounts for both within county serial correlation in the outcome and overdispersion (Wooldridge, 1999).

Our analysis of contraceptive purchasing behavior uses data at the store level and is described by the following equation:

$$
\operatorname{IHS}\left(Y_{s c t}\right)=\beta_{0}+\beta_{1} \text { Access }_{c t}+\beta_{2} X_{c t}+\gamma_{s}+\alpha_{t}+\varepsilon_{s c t}
$$

$\operatorname{IHS}\left(Y_{s c t}\right)$ is the inverse hyperbolic sine of expenditures on a particular set of products at store $s$, in county $c$, in month-year $t$. We use the IHS to address the possibility that there may be zero expenditures for a store in a particular month-year. $\beta_{1}$ is interpreted as a percentage change. The main outcome of interest in this analysis is expenditures on contraceptives, although we also

\footnotetext{
${ }^{34}$ These data are available only at the county-year level; we interpolate this measure across months within a year to avoid large jumps at the end of each year in the analyses using monthly data.

${ }^{35} \mathrm{We}$ use year fixed effects in the analyses using annual data and year-month fixed effects in the analyses using monthly data.
} 
examine purchases of other products as a falsification test. Conceptually, this estimating equation is the same as Eq. (1) as the treatment variables are still measured at the county level. Because the stores included in the Nielsen sample do not represent the universe of contraceptive purchases, and because the sample of stores is not representative at the county level, it would be inappropriate to aggregate these measures to the county level. Keeping the unit of analysis at the store-level allows for the inclusion of store fixed effects such that the estimates are identified off of deviations from store-level averages.

Identifying Assumption: The identifying assumption for estimating Eqs. (1) and (2) is that the variation in clinic access (family planning and abortion) is uncorrelated with other unobserved time-varying determinants of abortions, births, and contraceptive purchases. Stated differently, to interpret the estimated coefficients as causal it must be that in the absence of changes in access to family planning and abortion services, the outcomes would have continued on a similar trajectory in all counties. The econometric specification does a lot to mitigate endogeneity concerns. The inclusion of county and time fixed effects control for all time-invariant county-level factors and overall time effects that might influence the outcomes. In addition, controlling for the unemployment rate, log per capita income and demographic specific populations reduce concerns that county level time-varying characteristics that explain the outcomes are also correlated with clinic access. Finally, we show that our main results are robust to the inclusion of region-specific linear time trends (Table A2). ${ }^{36}$

While the identifying assumption is not directly testable, there is evidence supporting its plausibility. First, the timing of the post-2011 changes in clinic access coincide with the timing of the state-level legislative changes. As such, the legislation caused isolated and unanticipated shocks to the supply of clinics. The clinics that ended up being most affected did not select into treatment

\footnotetext{
${ }^{36}$ We use Texas Health and Human Services Regions, which are groupings of counties and there are 11 such regions in the state. Another possibility would be to include county-specific trends, although given that there are 254 counties in Texas (many of which are quite small), including a large number of additional parameters into a Poisson model would raise considerable concerns over an incidental parameters problem; indeed, in attempting to control for countyspecific linear time trends, these models often fail to converge. Furthermore, given the relatively non-linear (although parallel) trends in natality described in Figure 4, it is not clear whether the inclusion of any type of linear trend is appropriate.
} 
and were not affected as a result of market factors. ${ }^{37}$

Second, Figure 4 plots the trends in fertility rates over time disaggregated by highly and nonhighly affected counties. Highly-affected counties are those that experienced either a 25-mile increase in driving distance to the nearest abortion clinic or a 10-mile increase in driving distance to the nearest publicly-funded family planning clinic between January 2006 and May 2015. Nonhighly-affected counties are the complement. Importantly, in the pre-policy period (2006-2011) the two types of counties appear to be trending similarly, and then as the three policies roll out between 2011 and 2014, the trends begin to diverge.

Figure 4 also emphasizes the fact that fertility rates fell substantially in all regions during the Great Recession. To evaluate whether this poses a threat to the validity of our estimates, we test the sensitivity of the natality results to different starting years, 2006-2010, and find very similar results across all specifications, see Table A3. This exercise also provides another indirect test of the parallel trends assumption; if there are differential pre-treatment trends in the outcome, then one would expect the point estimates to substantively change as pre-treatment years are successively omitted.

Third, we employ a procedure similar to that used in Lahey (2014) and Lu and Slusky (2017) as another indirect test of the parallel trends assumption. Collapsing to the county level, we predict the change in access to each type of clinic occurring between 2011 and 2015 (the roll-out and post-period) using the change in fertility rates from the pre-period, 2006-2010. The endogeneity concern is that changes in fertility rates in the pre-period are correlated with changes in clinic access. If this is the case, it will be impossible to distinguish the true impact of clinic access on fertility from changes in fertility due to some other unobserved factor. As presented in Table 2, there is no detectable evidence of a relationship between pre-period changes in fertility rates and subsequent changes in clinic access, further supporting the identifying assumption.

\footnotetext{
${ }^{37}$ Because our measure of access is the distance to the nearest clinic of each type at each period in time, it is possible that the changes in access we observe are not directly related to the legislation that we are studying. Indeed, Figure 4 shows a small percentage of the population is defined as "affected" prior to 2011. That being said, the vast majority of the variation that we exploit occurs in the post-legislation period, and the insensitivity of the estimates to the exclusion of these earlier years (Table A3) assuages this concern.
} 
Finally, another potential confound is if the state of Texas enacted other policies that changed abortion and fertility rates at the same time, in the same way, and for the same counties as the budget cuts to family planning clinics or the more stringent abortion clinic regulations. We have found no evidence supporting this concern. ${ }^{38}$ The Affordable Care Act (the ACA) was implemented during the sample frame; while the ACA did affect reproductive services, Texas opted out of the Medicaid expansions, including the Medicaid family planning expansion. ${ }^{39}$

\section{Results}

\subsection{Outcome: Abortions}

Table 3 presents estimates of the effect of clinic access on within-Texas abortions. Each estimate in the table comes from a separate regression (see Eq. (1)) where Panel A reports results for abortion clinic access and Panel B for family planning clinic access. Within a panel, each row presents a different binary measure of clinic access, where clinic access measures become more extreme moving down the columns. Moving across the table, each successive column includes additional controls. Column 4 is the preferred specification as it includes economic and demographic controls and a control for access of the other type of clinic (e.g., family planning clinics in the case of abortion). We test the sensitivity of our estimates to non-linear controls of distance (for our main specifications for abortion and family planning services), and the estimates remain virtually unchanged for both abortion and family planning (results not reported). ${ }^{40}$

\footnotetext{
${ }^{38}$ On September 1, 2005 Texas implemented an emergency contraceptive access law which required hospitals to inform victims of sexual assault about emergency contraceptives (e.g., Plan B). This date, however, predates our analysis period, which is 2006-2015. Also, greater access to Plan B would only dampen our results. Additionally, on August 24, 2006 a federal law was passed granting all individuals 18 and older access to emergency contraceptives in pharmacies without prescriptions. This law was expanded to include 17-year-olds on April 22, 2009 (Guttmacher).

${ }^{39}$ Source: http://www.kff.org/report-section/medicaid-and-family-planning-the-aca-medicaid-expansion-andfamily-planning/. For these federal policies, there is no reason to believe they would differentially affect the same counties in Texas that were affected by reduced access to family planning and abortion.

${ }^{40}$ The sample size in these regressions is 2,277 , representing 253 counties over 9 years. Note that we only use 253 counties in all regressions because there is one very small county for which age-specific population counts are equal to zero. The Poisson model cannot be estimated with an exposure variable equal to zero, so in certain age-specific regressions this county had to be omitted, and we chose to omit this county from all regressions for consistency.
} 


\section{Access to Abortion Clinics}

Panel A, column 4 shows that when there is no abortion clinic within 25 miles, within-Texas abortions decline by $18 \%$ relative to having at least one clinic within 25 miles. ${ }^{41}$ As expected, as this measure becomes more extreme, the effect grows in magnitude; no clinic within 100 miles is associated with about a 33\% reduction in within-Texas abortions relative to having at least one clinic within 100 miles. These results are robust to varying levels of controls.

While our regression specification is different and thus not directly comparable because they categorize distance into bins, Cunningham et al. (2017) estimate that having no abortion clinic within 100 to 200 miles is associated with an increase in abortions of $32 \%$ relative to having a clinic within 25 miles. Estimates from our most similar specification imply that abortions rise by 33\% in Texas if there is no clinic within 100 miles relative to having a clinic within 100 miles. In a short paper, for counties that became 50 to 99 miles away from an abortion clinic between 2012 and 2014, Grossman et al. (2017) estimate that abortions fell 35.7\%, an effect slightly larger than our own but within the confidence interval of our basic specification.

Recall that our estimates only represent the impacts of access to abortion clinics on abortions occurring within Texas. We do not observe mother's county of residence for Texas women receiving abortions outside of Texas and therefore cannot determine if decreased access to abortion in Texas leads to a total net change in the number of abortions.

That being said, Figure 5 provides evidence that Texas women are traveling to nearby states to obtain abortions when access becomes restricted in Texas. Although this figure is descriptive in nature, it shows a decline in within-Texas abortion rates that roughly coincides with the Texas legislation, and an increase in the share of abortions provided to non-residents in states that surround Texas. In particular, Figure 5 shows a sharp increase in the share of abortions to out-of-state residents in New Mexico and Arkansas, suggesting that Texas women are traveling to these states. In summary, it appears that the reduction in within-Texas abortions is at least in part offset by women traveling to nearby states. Even with more comprehensive data (i.e., data covering abor-

\footnotetext{
${ }^{41}$ Note that the average driving distance to an abortion clinic is about 26 miles.
} 
tions to Texas residents in states outside of Texas by their county of residence), we would surely miss counting some abortions. For example, in Mexico, misoprostol, a drug used to induce an abortion, is available without a prescription.

Due to the difficulties of measuring the number of abortions, we place more focus on the birth results. The effects of changes to the abortion clinic market on abortions, however, demonstrate that the intended mechanisms behind our birth results are at play.

\section{Access to Family Planning Clinics}

Panel B of Table 3 reports results for the effect of family planning clinic access on within-Texas abortions. Ex ante it is unclear whether one should expect there to be a relationship - and if there is, whether it is likely to be positive or negative - since family planning clinics do not provide abortions. On one hand, reduced access to family planning could lead to a reduction in abortions because there are fewer informal referrals to abortion clinics, but if reduced access to family planning leads to more unintended pregnancies (as we expect), then abortions may increase. Overall, we find no consistent pattern in the impacts of reduced access to family planning on abortions.

\subsection{Outcome: Births}

To this point we have shown that the shock to the supply of abortion clinics is associated with a reduction in the number of in-state abortions. Ideally we would like to estimate the effect of reduced clinic access on net abortions, but our data only report abortions occurring within the state of Texas. Even if we were to obtain abortion counts from other states, due to the controversial nature of these services, cross-state abortion reporting is quite poor and is likely underreported. As such, we turn to birth data and ask the following question: Does the reduction in the number of abortions in Texas translate to a proportional increase in births, or are Texas women finding alternative ways to avoid unplanned births?

The Natality files have several advantages. First, they are quite complete as they report nearly all births that result in a birth certificate. Second, they code mother's county of residence regardless 
of where the birth occurs. Finally, these files report month of birth rather than year of birth as the abortion data do allowing for a more precise merge with the clinic closure and funding cut dates.

\section{Access to Abortion Clinics}

Table 4 is structured similar to Table 3, except that the outcome is the number of births rather than abortions. Panel A shows that across several specifications which vary the level of controls, a reduction in abortion clinic access is consistently associated with an increase in births. Specifically column 4 shows that no clinic within 25 miles leads to a $1.8 \%$ increase in births relative to having at least one clinic within 25 miles (row 1), and the 50-mile measure indicates a $3.1 \%$ increase in births relative to having at least one clinic within 50 miles.

As in the previous table, the measure of clinic access becomes more extreme moving down the columns, and one would expect to observe larger birth effects with more extreme measures. However, this pattern does not hold as strongly for births as the point estimate for the 100-mile measure $(1.9 \%)$ is somewhat smaller than that of the 50-mile measure. We should caution that these estimates are not measured precisely enough to reject that the 50-mile and 100-mile estimates are the same. Furthermore, it is possible that the estimates for the more extreme measures are smaller because, at least anecdotally, there is evidence that several non-profits, including Fund Texas Choice, targeted the areas that were most heavily affected; labelling them "abortion deserts". Their main objective was to provide transportation and lodging for women seeking to travel to an abortion clinic. If these non-profits were effective, then any positive birth effects would be dampened in the regions they serve.

\section{Access to Family Planning Clinics}

Panel B reports the contemporaneous relationship between family planning clinic access and births. Similar to the abortion analysis presented in Panel B of the previous table, we find no consistent patterns across the different specifications (columns 1-4) and many of the point estimates are imprecisely measured. It should be kept in mind, however, that the estimates presented here assign 
family planning access to births at the time of conception. Although a natural place to begin, this assignment is somewhat arbitrary. There is little reason to believe that reduced clinic access should affect births immediately. First, if a woman is using short acting hormonal contraceptives such as the pill, patch or ring, then she may have a stock as one can obtain up to three months supply at a time. Second, in order to obtain (or renew) a prescription for contraceptives, one must undergo an annual exam from a licensed physician. Third, LARCs such as implants, injections or IUDs, last anywhere from 3 to 10 years depending on the brand and type. Consequently, there is no obvious $a$ priori expectation about the specific dynamic structure of the relationship between access to family planning and births.

To probe the idea of lagged family planning access, we employ the "no funded clinic within 25 miles" measure and modify Eq. (1) to include various lags. These results are presented in Table 5. For comparison purposes, the specification presented in column 1 only includes the contemporaneous measure. Columns 2-4 successively add in year lags such that column 4 includes the contemporaneous effect, as well as a one, two and three year lag in the same regression. This exercise reveals that there is consistently a larger effect on the 12 month lag that is statistically different from zero, and this effect holds across varying levels of controls (compare row 2 of Panels A and B). No publicly-funded family planning clinic within 25 miles is associated with a $1.3 \%$ increase in births that are conceived 12 months from the time at which access is measured. ${ }^{42}$ In exploring the heterogeneous impacts of births in the following section, both the contemporaneous and 12 month lags for this measure of family planning access are reported.

For comparison, we contrast our results with Lu and Slusky (2017), who use variation in access to one single large provider of family planning services through the year 2013. Using a linear family planning access measure without controls for abortion clinic access, they find that an increase of 25 miles to the nearest clinic translates into a 0.3 percent increase in the birth rate. Our larger estimates may be due to our broader measure of family planning access.

\footnotetext{
${ }^{42}$ For the outcomes involving abortion rates, we also experimented with different lags of family planning access, but the results did not qualitatively change. That is, there continued to be mixed evidence of effects of publicly-funded family planning access on abortion rates.
} 


\subsection{Birth Heterogeneity}

To understand whether different subpopulations are affected differently by the changing landscape for reproductive services, we estimate how the effects of access vary across maternal age, parity, mother's ethnicity, mother's education, and mother's marital status. Tables A4 to A6 display the estimates for these groups. Similar to the previous tables, estimates of abortion clinic access are reported in Panel A; Panel B now reports the contemporaneous effect (row 1) and the twelve month lag (row 2) for family planning access as this is where the impacts of reduced access to family planning are concentrated. Table A4 reports results by age of mother, Table A5 by birth parity, and Table A6 by ethnicity, education, and marital status. We discuss the heterogeneity patterns for each type of clinic in turn.

\section{Access to Abortion Clinics}

As evident by Table A4 Panel A, we find no significant effects of abortion clinic access for teen mothers; rather the effects are concentrated among older mothers. Having no clinic within 50 miles is associated with a 3.3 percent increase in births for mothers in their 20s, a 4.4 percent increase for mothers in their 30s, and 10.8 percent increase in abortions for mothers ages $40-44$. While the impacts for mothers ages 40-44 are particularly large, it is worth noting that these estimates are identified off of a relatively small number of births - in our sample births to women ages 40-44 represented only $2.2 \%$ of all births.

Table A5 Panel A reveals that the increase in births as a result of abortion clinic closures is driven by women who already have at least one child. We find no evidence of an increase in births among mothers who do not already have children (first parity). These estimates suggest that having no clinic within 50 miles is associated with an approximate $5 \%$ increase in births for women who already have one, two, or at least three children.

Results by three additional mother characteristics - ethnicity, education and marital status - are reported in Table A6 Panel A. In general, estimates for Hispanic women are relatively larger than for non-Hispanic women, and for low education women compared to high education women. The 
most stark differences appear between married and unmarried mothers. When there is no abortion clinic within 50 miles, births to married mothers increase by $4.6 \%$ while the estimate for unmarried mothers is only $1.1 \%$ and indistinguishable from zero.

Together, these results paint a picture of the types of mothers who change their childbearing behavior in response to decreased access to abortion. There are several explanations for these findings. Married mothers who already have children are not necessarily "more affected" by the reduced access to abortion clinics. That is, there is no reason to believe the cost of seeking an abortion is greater for this group compared to other women. In fact, one could argue that older married women may be more likely to have the resources to travel to seek an abortion. However, it is possible that these women are more likely to be on the margin of the decision to seek an abortion. If individuals view having a child as costly, then it is reasonable to argue that the marginal cost of an additional child is smaller for women who already have at least one child, and for women who have a stable partner. Finally, because the marginal cost of having a first child is relatively high, it is not implausible that some women - in particular younger women - may take precautionary measures to avoid pregnancy in the first place. In Section 5.4 we provide evidence suggesting that at least some women are engaging in precautionary behaviors.

\section{Access to Family Planning Clinics}

Similar to the main estimates for access to family planning, there is no statistically significant impacts for access to family planning at the time of conception on births across any subgroup. As such, we focus on the 12-month lagged measures of access to family planning for the remainder of this section.

The age-specific estimates presented in Panel B of Table A4 reveal a statistically significant increase in births among teen mothers and mothers in their 30s. Packham (2016) estimates that the 2011 Texas family planning cuts led to teenage birth rates rising by $3.4 \%$ where the effect is driven by increases in births two years after the policy change. Her estimates are not directly comparable to our own since her estimates capture of the effect of the cuts rather than the effect of increased 
distance to a publicly-funded provider. ${ }^{43}$ However, it is reaffirming that we also find evidence of effects on teenagers. There is no detectible effect for women in their 20s, although it is not possible to rule out effect sizes of well over $1 \%$ given the size of the standard errors. The impacts measured for women age 40-44 are large but imprecise.

Similar to the abortion clinic results, Panel B of Table A5 presents evidence that reduced access to publicly-funded family planning clinics increase the number of births to mothers who already have children.

Finally, the estimates in Table A6 Panel B show no meaningful differences in effects by ethnicity. The estimates on family planning are relatively larger for low education women compared to high education women (not surprising given that low education women are the target audience for these clinics), and relatively larger for married women compared to unmarried women, although these differences are not precisely estimated.

Because these differences lack precision, one should take caution with the interpretation. That said, the overall findings do confirm what is known about access to publicly-funded family planning services during this period. First, these clinics aim to serve young mothers (especially teens) and low income women (for which low education is a proxy), and thus it is unsurprising our results show reduced access to publicly-funded family planning increases births among teen and low education mothers. There is also reason to believe that married women who already have children would be particulary impacted by these restrictions in access: the funding cuts in question dramatically hampered the ability of these clinics to offer long-acting reversible contraceptives (LARCs). ${ }^{44}$ Childless women are much less likely to use LARCs than women with children (Branum and Jones, 2015). Thus, the decreased access to subsidized LARCs may have fallen heavily on women with children.

\footnotetext{
${ }^{43}$ Packham (2016) compares counties in Texas with at least one publicly-funded clinic with counties outside of Texas.

${ }^{44}$ Stevenson et al. (2016) estimated that just one of the pieces of legislation in Texas that we examine (the changes to the Medicaid fee-for-service program) resulted in a 35.5\% reduction in Medicaid claims for LARCs, and a $31.1 \%$ reduction in Medicaid claims for injectable contraceptives.
} 


\subsection{Outcome: Contraceptive Purchases}

In this section we aim to test if individuals change their sexual behavior - in particular, whether they take up precautionary measures to prevent pregnancy - after learning about restrictions in access to abortion. HB2 was highly-publicized statewide and nationally so it is not inconceivable that at least some individuals may attempt to take more caution.

Estimates from Eq. (2) for abortion access are reported in Panel A of Table 6. Note the outcome, contraceptive expenditures, is transformed using the inverse hyperbolic sine function so the treatment effects should be interpreted as percentage changes.

In general, the estimates support the hypothesis of increased take-up of precautionary measures. We find across all specifications that reduced access to abortion leads to increases in contraceptive expenditures. This finding is consistent with Sabia and Anderson (2016) who show that parental involvement laws - laws that require minors to obtain parental consent before receiving an abortion and thus increasing the cost of abortion for this group - are associated with an increase in the probability that sexually active minor teen females use birth control. That said, our estimates are not stable upon the inclusion of varying controls (the coefficient on the 50-mile treatment decreases in size from $11.0 \%$ with no controls to $4.1 \%$ with all controls), and our preferred estimates that include all controls are not statistically different from zero.

To assess how reliable our contraceptive estimates are, we conduct a falsification test in which we estimate the impacts of restricted access to abortion on expenditures for 17 products that should be unrelated to abortion access. The results of this test are presented in Figure A1 and show that the impacts we estimate for contraceptives do appear to be an outlier in the models that do not include controls (although the estimates for one other product group are statistically different from zero at the 5\% level as well). Taken as a whole, we view this as suggestive evidence that reduced access to abortion led to an increase in precautionary behavior.

Now consider the estimates for family planning access in Panel B of Table 6. The hypothesis we seek to test here is whether individuals are substituting away from contraceptives provided by family planning clinics toward over-the-counter contraceptives. To give a sense of the size of the 
effect on family planning services, using Medicaid claims data, Stevenson et al. (2016) estimate a $30 \%$ decline in contraceptive claims in response to the Women's Health Program. Similar to the birth effects, we find no statistically significant effect of access to family planning on contraceptive expenditures at the time of purchase. However, a one-year lag in access to family planning is associated with an increase in contraceptive expenditures, consistent with the idea that women eventually run out of contraceptive supplies provided by family planning clinics. These estimates are much less sensitive to our choice of controls compared to the estimates for abortion access. Furthermore, the falsification test we conduct for family planning - presented in Figure A2 - provides evidence that the estimates for contraceptives represent an outlier compared to the other categories as the point estimates are larger than that of any other category and are marginally statistically significant (although two other estimates are marginally significant as well). We conclude that these estimates provide at least suggestive evidence in support of the hypothesis that individuals are substituting toward over-the-counter contraceptives.

For both access to abortion and family planning, the evidence clearly suggests the take-up of precautionary measures and the substitution toward forms of over-the-counter contraceptives. Both imply that the estimated birth effects would have been larger in the absence of this behavior.

\section{Discussion and Conclusion}

In recent years, there has been much debate about access and public funding of reproductive services. For example, under the Affordable Care Act (the ACA), states have the option of expanding their state's Medicaid coverage including family planning coverage. However, one of the main tenets of support for repealing the ACA involves halting these expansions and restricting the funding of reproductive services. In this paper, we attempt to understand how restrictions in access to both abortion and family planning providers affect abortions, births, and contraceptive purchases. We leverage changes in the market for reproductive services in Texas, which are similar to those being discussed nationally. In response to an abortion clinic closure within 50 miles, births rose $3 \%$ 
whereas the birth effects of no longer having a publicly-funded family planning clinic within 25 miles were smaller at $1 \%$. A $1 \%$ increase in births is comparable to the effects of an abortion clinic act on violence on births (Jacobson and Royer, 2011). There is suggestive evidence that individuals were forward-looking in response to the changing environment for reproductive services - limited abortion and family planning access is correlated with increases in contraceptive purchases. Backof-the-envelope calculations imply that by the end of 2015, the abortion clinic restrictions lead to 2,562 additional births and the changes in funding to family planning clinics increased births by 668. These calculations, however, miss other important costs of reduced access - most importantly, the increased travel cost for women seeking abortion or family planning services.

Our analysis is a case study of one state. Thus, generalizing these findings to other settings is challenging. However, given the resemblance of current debated legislation at the federal level with the policies already implemented in Texas, we view our analysis as providing a useful benchmark of the potential impacts of recent proposed policies. 


\section{References}

Akerlof, George A, Janet L Yellen, and Michael L Katz, "An analysis of out-of-wedlock childbearing in the United States," The Quarterly Journal of Economics, 1996, 111 (2), 277-317.

Ananat, Elizabeth Oltmans and Daniel M Hungerman, "The Power of the Pill for the Next Generation: Oral Contraception's Effects on Fertility, Abortion, and Maternal and Child Characteristics," Review of Economics and Statistics, 2012, 94 (1), 37-51.

Averett, Susan L, Daniel I Rees, and Laura M Argys, "The Impact of Government Policies and Neighborhood Characteristics on Teenage Sexual Activity and Contraceptive Use," American Journal of Public Health, 2002, 92 (11), 1773-1778.

Bailey, Martha J, "More power to the pill: the impact of contraceptive freedom on women's life cycle labor supply," The Quarterly Journal of Economics, 2006, 121 (1), 289-320.

_ , "'Momma's Got the Pill": How Anthony Comstock and Griswold v. Connecticut Shaped US Childbearing," American Economic Review, 2010, 100 (1), 98-129.

_ , "Reexamining the Impact of Family Planning Programs on U.S. Fertility: Evidence from the War on Poverty and the Early Years of Title X," American Economic Journal: Applied Economics, 2012, 4 (2), 62-97.

_ , "Fifty Years of Family Planning: New Evidence on the Long-Run Effects of Increasing Access to Contraception," Brookings Papers on Economic Activity, Economic Studies Program, The Brookings Institute, 2013, 46 (1), 341-409.

Bitler, Marianne and Madeline Zavodny, "The effect of abortion restrictions on the timing of abortions," Journal of Health Economics, 2001, 20 (6), 1011-1032.

Blank, Rebecca M, Christine C George, and Rebecca A London, "State abortion rates the impact of policies, providers, politics, demographics, and economic environment," Journal of Health Economics, 1996, 15 (5), 513-553.

Branum, Amy M and Jo Jones, Trends in long-acting reversible contraception use among US women aged 15-44 number 2015, US Department of Health and Human Services, Centers for Disease Control and Prevention, National Center for Health Statistics, 2015.

Buchmueller, Thomas C, Mireille Jacobson, and Cheryl Wold, "How Far to the Hospital?: The Effect of Hospital Closures on Access to Care," Journal of Health Economics, 2006, 25 (4), $740-761$.

Cameron, A Colin and Pravin K Trivedi, Regression Analysis of Count Data, Vol. 53, Cambridge University Press, 2013.

Colman, Silvie, Thomas S Dee, and Ted Joyce, "Do Parental Involvement Laws Deter Risky Teen Sex?," Journal of Health Economics, 2013, 32 (5), 873-880. 
Cunningham, Scott, Jason M Lindo, Caitlin Myers, and Andrea Schlosser, "How Far Is Too Far? New Evidence on Abortion Clinic Closures, Access, and Abortions," NBER Working Paper No. 23366, 2017.

Donald, Stephen G and Kevin Lang, "Inference with difference-in-differences and other panel data," The Review of Economics and Statistics, 2007, 89 (2), 221-233.

Fund Texas Choice, "What is HB2?," 2014.

Goldin, Claudia and Lawrence F Katz, "The Power of The Pill: Oral Contraceptives and Women's Career and Marriage Decisions," Journal of Politcal Economy, 2002, 110 (4), 73070.

Gross, Tal, Jeanne Lafortune, and Corinne Low, "What Happens the Morning After? The Costs and Benefits of Expanding Access to Emergency Contraception," Journal of Policy Analysis and Management, 2014, 33 (1), 70-93.

Grossman, Daniel, Kari White, Kristine Hopkins, and Joseph E Potter, "Change in Distance to Nearest Facility and Abortion in Texas, 2012 to 2014," Journal of American Medical Association, 2017, 317 (4), 437-439.

Guldi, Melanie, "Fertility Effects of Abortion and Birth Control Pill Access for Minors," Demography, 2008, 45 (4), 817-827.

Jacobson, Mireille and Heather Royer, "Aftershocks: The Impact of Clinic Violence on Abortion Services," American Economic Journal: Applied Economics, 2011, 3 (1), 189-223.

Jatlaoui, Tara C, “Abortion surveillance - United States, 2013," MMWR. Surveillance Summaries, 2016, 65.

Jones, Rachel K and Jenna Jerman, "Abortion incidence and service availability in the United States, 2011," Perspectives on Sexual and Reproductive Health, 2014, 46 (1), 3-14.

_ and _, "Abortion incidence and service availability in the United States, 2014," Perspectives on Sexual and Reproductive Health, 2017, 49 (1), 17-27.

Joyce, Theodore and Robert Kaestner, "State reproductive policies and adolescent pregnancy resolution: the case of parental involvement laws," Journal of Health Economics, 1996, 15 (5), 579-607.

_, , , and Silvie Colman, "Changes in abortions and births and the Texas parental notification law," New England Journal of Medicine, 2006, 354 (10), 1031-1038.

Kane, Thomas J and Douglas Staiger, "Teen motherhood and abortion access," The Quarterly Journal of Economics, 1996, 111 (2), 467-506.

Kearney, Melissa S and Phillip B Levine, "Subsidized Contraception, Fertility, and Sexual Behavior," The Review of Economics and Statistics, 2009, 91 (1), 137-151. 
Lahey, Joanna N, "Birthing a Nation: The Effect of Fertility Control Access on the NineteenthCentury Demographic Transition,” The Journal of Economic History, 2014, 74 (2), 482.

Levine, Phillip B, "The Sexual Activity and Birth-Control Use of American Teenagers," in "Risky Behavior Among Youths: An Economic Analysis," University of Chicago Press, 2001, pp. 167218.

_ , "Parental Involvement Laws and Fertility Behavior," Journal of Health Economics, 2003, 22 (5), 861-878.

Lindo, Jason $M$ and Analisa Packham, "How Much Can Expanding Access to Long-Acting Reversible Contraceptives Reduce Teen Birth Rates?,” Technical Report 2015.

Lu, Yao and David JG Slusky, "The Impact of Women's Health Clinic Closures on Fertility," 2017.

Packham, Analisa, "Family Planning Funding Cuts and Teen Childbearing," 2016.

Sabia, Joseph J and D Mark Anderson, "The effect of parental involvement laws on teen birth control use," Journal of Health economics, 2016, 45, 55-62.

Stevenson, Amanda J, Imelda M Flores-Vazquez, Richard L Allgeyer, Pete Schenkkan, and Joseph E Potter, "Effect of Removal of Planned Parenthood from the Texas Women's Health Program," New England Journal of Medicine, 2016, 374 (9), 853-860.

Texas 83rd State Legislature, “Texas HB No.2,” 2013.

Weber, Sylvain, Martin Péclat et al., "GEOROUTE: Stata module to calculate travel distance and travel time between two addresses or two geographical points," Statistical Software Components, 2016.

White, Kari, Kristine Hopkins, Abigail RA Aiken, Amanda Stevenson, Celia Hubert, Daniel Grossman, and Joseph E Potter, "The Impact of Reproductive Health Legislation on Family Planning Clinic Services in Texas," American Journal of Public Health, 2015, 105 (5), 851-858.

Wooldridge, Jeffrey M, "Distribution-Free Estimation of Some Nonlinear Panel Data Models," Journal of Econometrics, 1999, 90 (1), 77-97.

Zolna, MR and JJ Frost, "Publicly funded family planning clinics in 2015: Patterns and trends in service delivery practices and protocols," 2016. 
Figure 1: Statewide - Synthetic Control

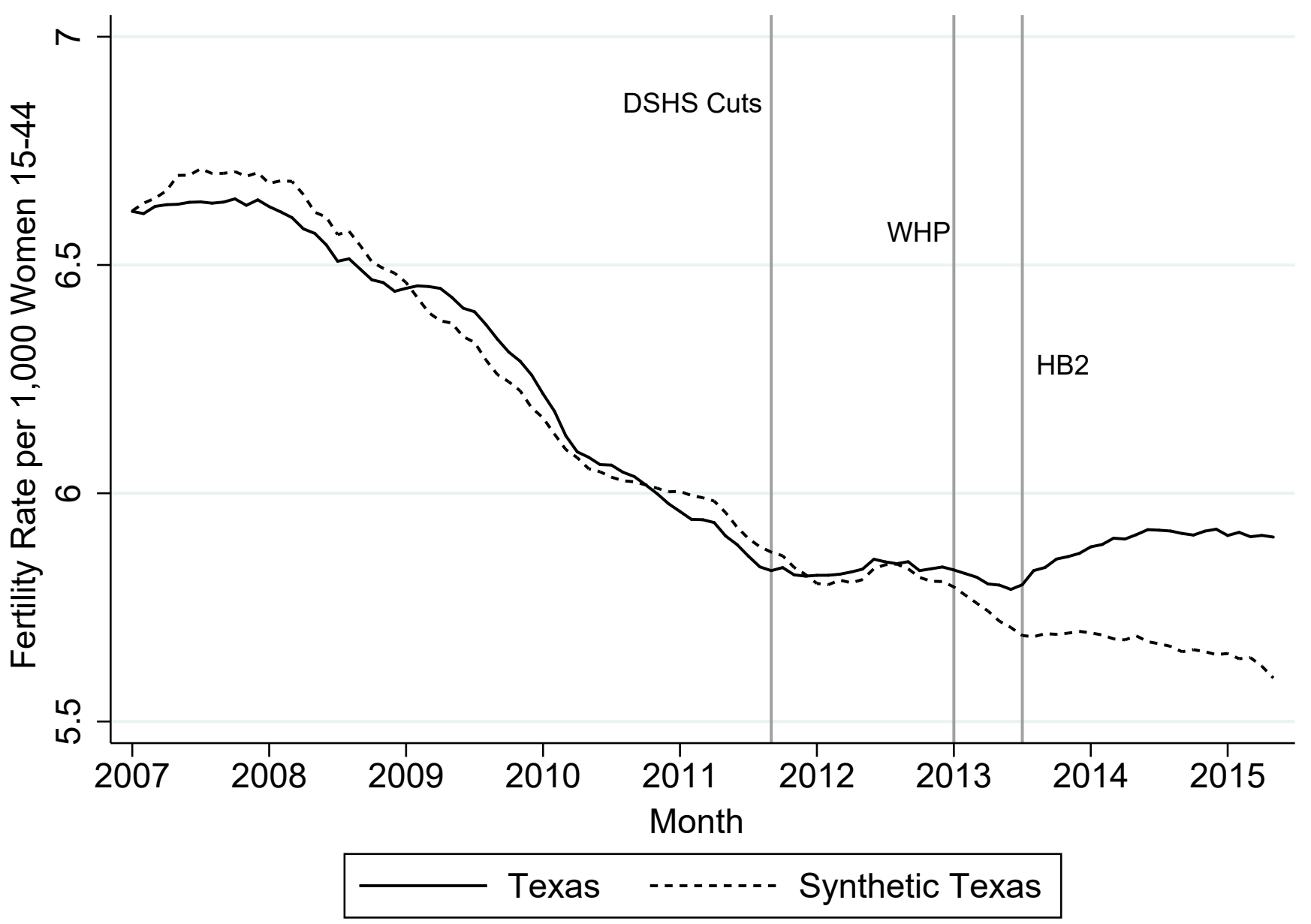

Note: Synthetic Texas is constructed by matching on the following: fertility rates (the outcome) prior to September 2011 (i.e., the date of DSHS cuts), the proportion of the population Hispanic and the proportion of the population of childbearing age (15-44) both measured at the 2010 census. The potential donor pool consists of all other U.S. states, and the matching procedure results in the selection of three donor states (California: 28.5\%; New Mexico: 47.8\%; Utah: 23.7\%). The synthetic control and all resulting estimates are constructed using monthly data; the plot uses 12-month moving averages to smooth seasonal variation in fertility rates. A regression of treatment-control differences on a post treatment indicator reveals an increase in the monthly fertility rate of 0.158 (Donald and Lang (2007) standard error of 0.068 ). This represents a $2.6 \%$ effect relative to the mean monthly fertility rate in Texas of 6.14 . 
Figure 2: Change in Access to Abortion Clinics

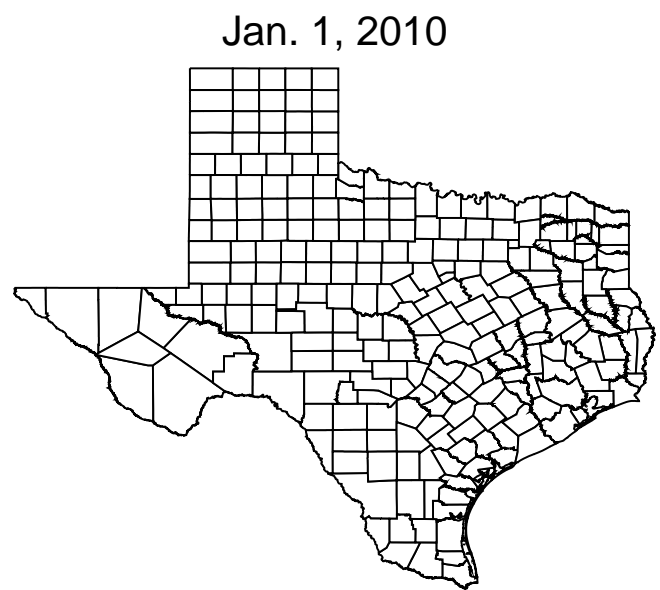

Jan. 1, 2013

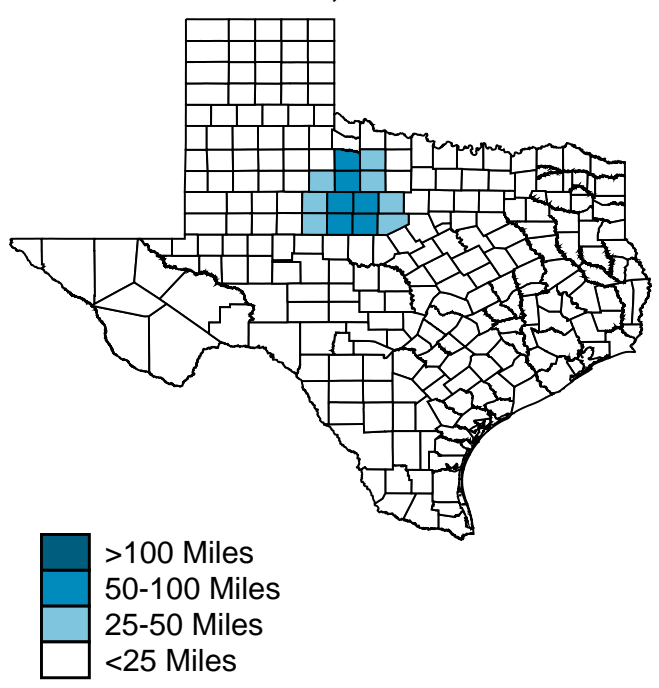

Jan. 1, 2012

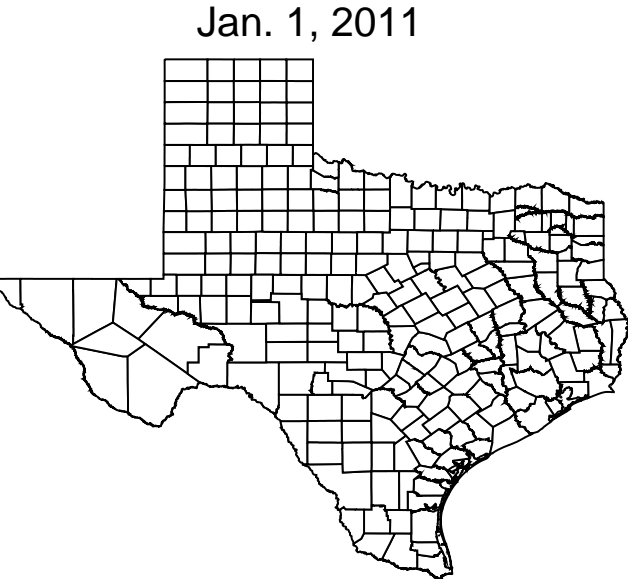

Jan. 1, 2014
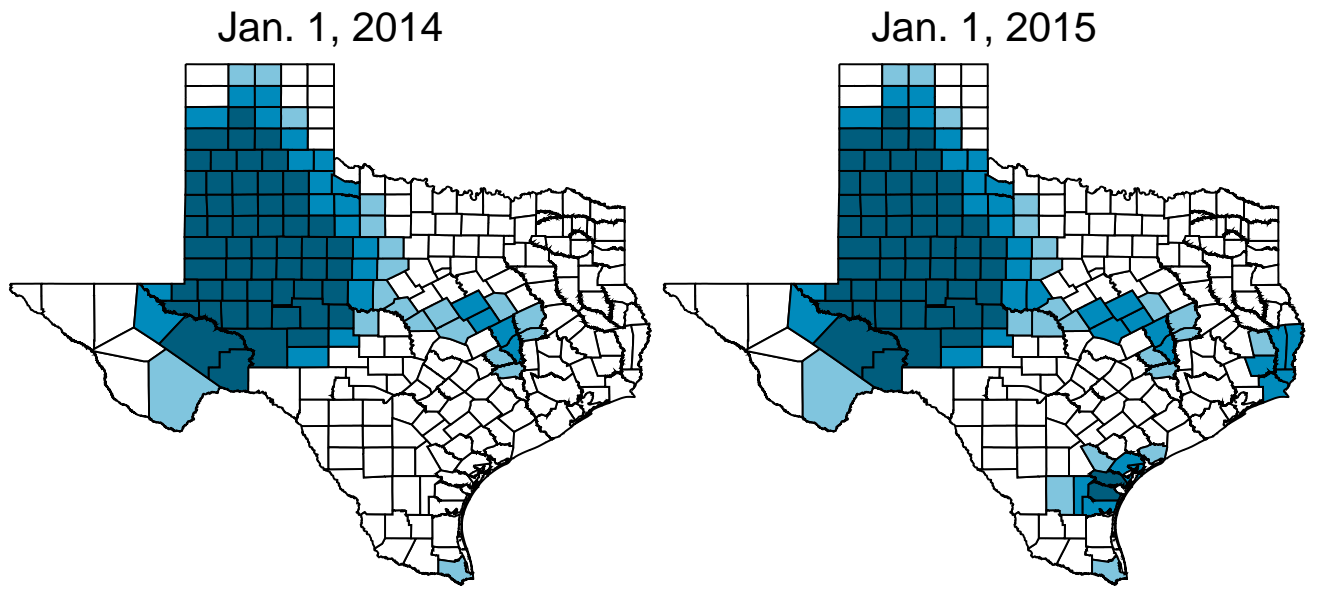

Note: Change in access is defined as the change in distance between the date in question and January 1, 2009. Distances are measured as miles driving from each county's population-weighted centroid to the nearest clinic that provides abortion services. Note that the period of minimum access occurred in mid-2014, during a period in which a clinic in McAllen, TX (near the southern tip of the state) closed for approximately six months; in this period, several counties near McAllen experienced a change in access of more than 100 miles. 
Figure 3: Change in Access to Publicly-Funded Family Planning Clinics

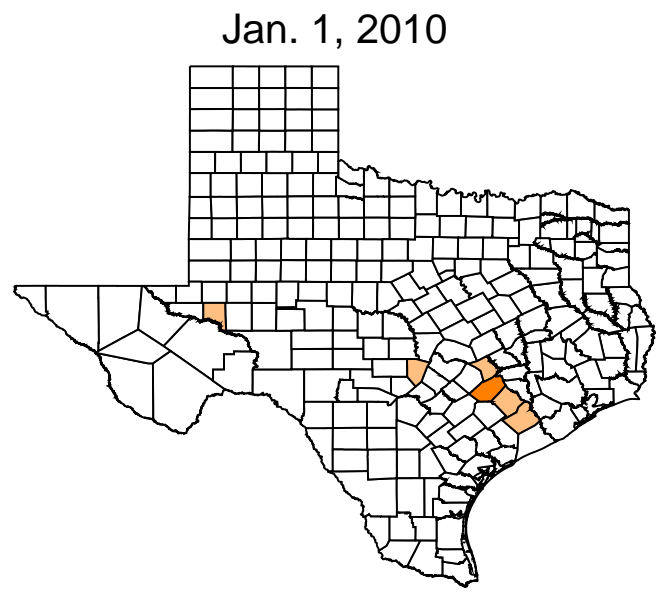

Jan. 1, 2013

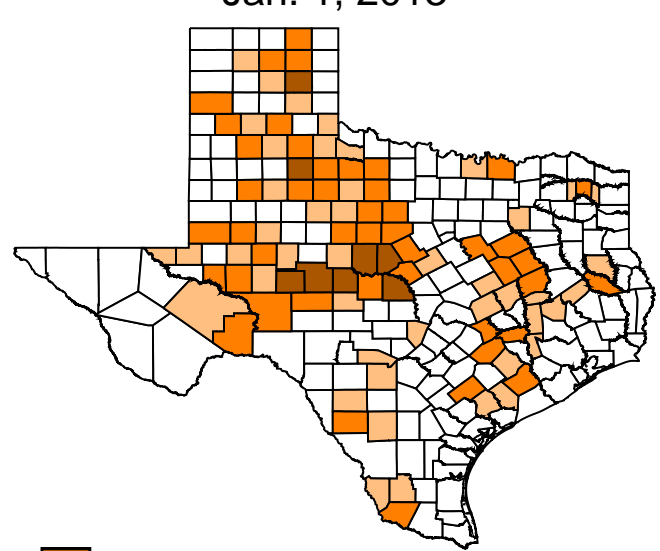

$>50$ Miles

25-50 Miles

10-25 Miles

$<10$ Miles

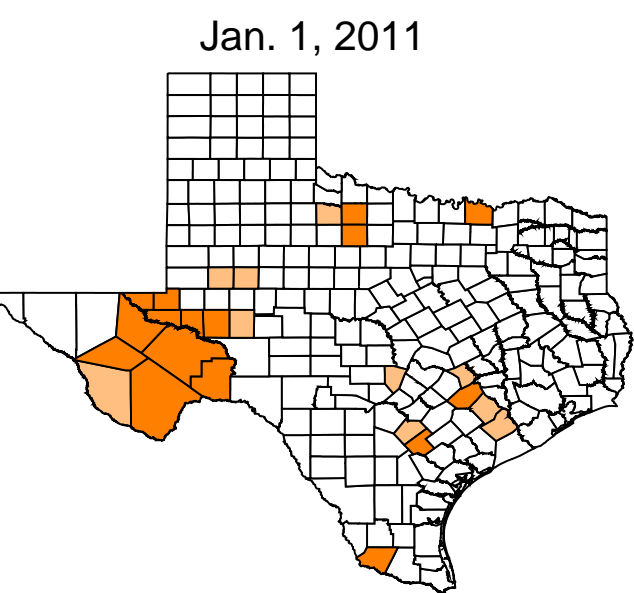

Jan. 1, 2014
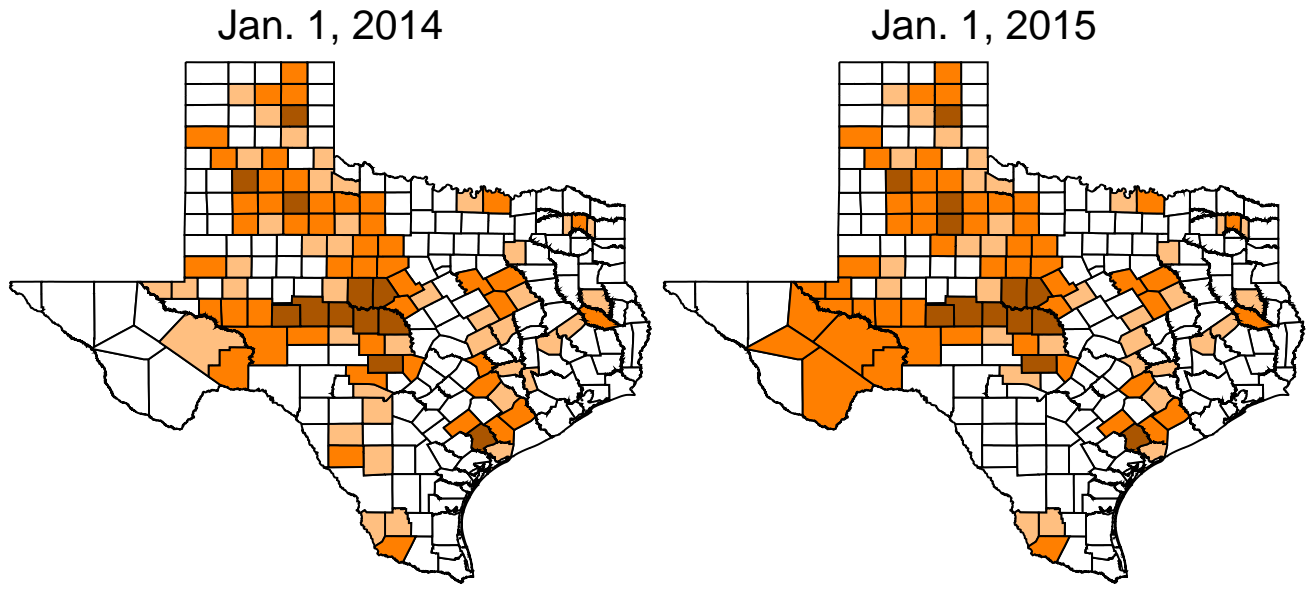

Note: Change in access is defined as the change in distance between the date in question and January 1, 2009. Distances are measured as miles driving from each county's population-weighted centroid to the nearest publicly-funded clinic that provides family planning services. 
Figure 4: Within State - Natality Trends

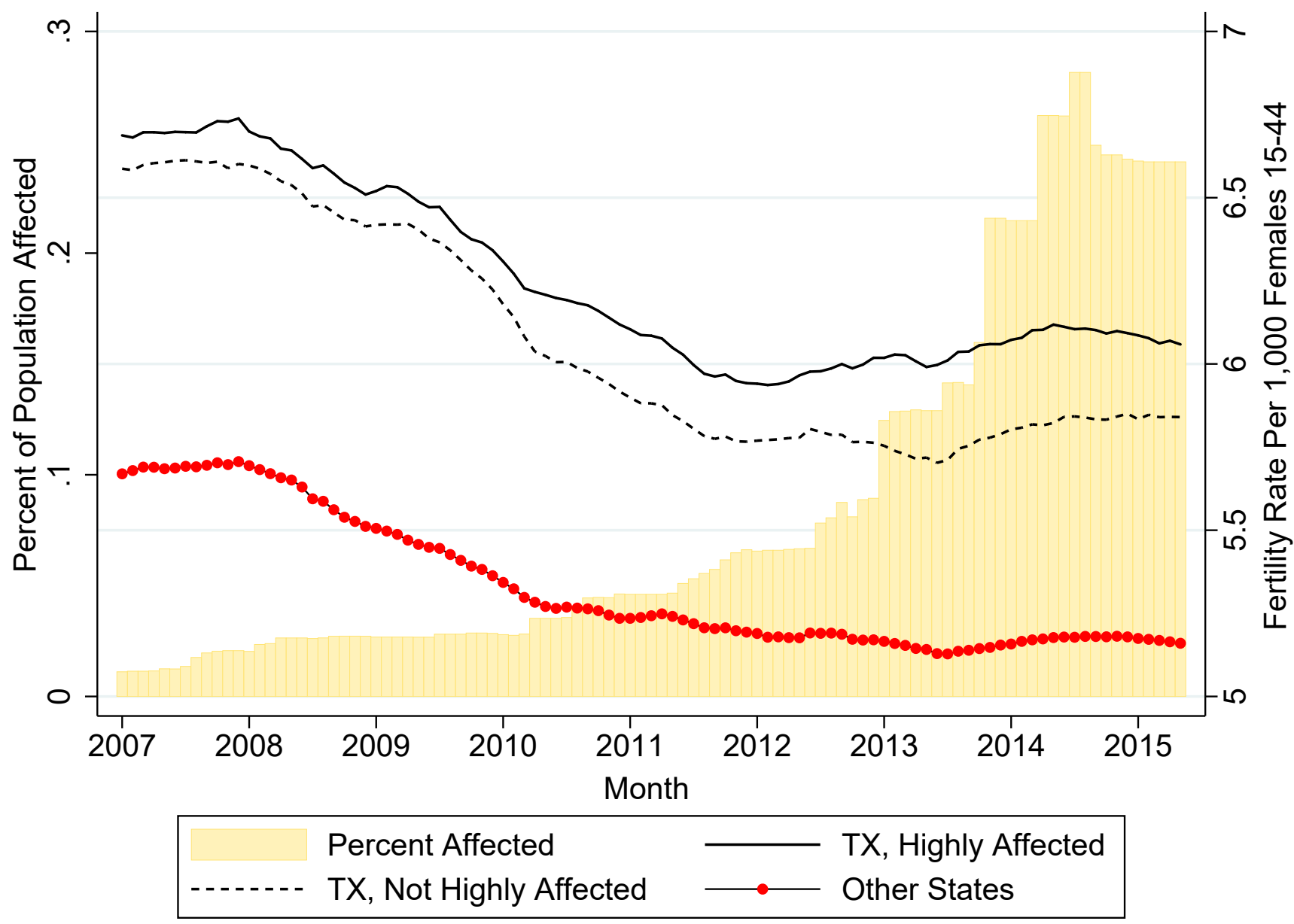

Note: "Highly Affected" counties in Texas are defined as those that ever experienced either a 25-mile increase in driving distance to the nearest abortion clinic or a 10-mile increase in driving distance to the nearest publicly-funded family planning clinic between the start of the sample in January 2006 and the end of the sample in May 2015. "Percent affected" represents the proportion of the Texas population in each period that experienced either such increase in driving distance between the start of the sample and the corresponding period. The plot uses 12-month moving averages to smooth seasonal variation in fertility rates. 
Figure 5: Out of State Abortion Rates by State

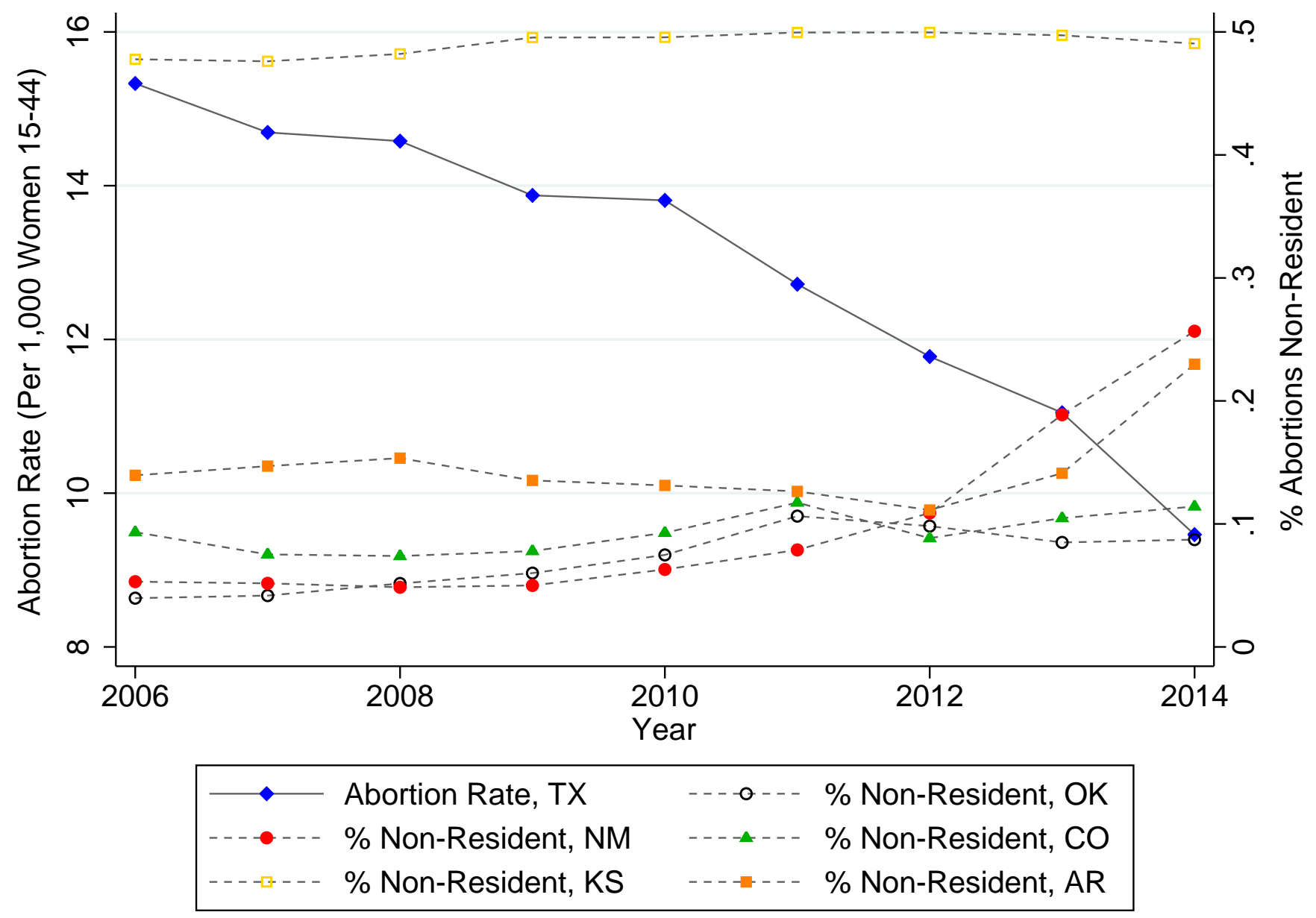

Note: The data come from each state's Department of Health. Abortion rates in Texas are constructed as rates per 1,000 women aged 15-44. We have also collected data on out-of-state abortions for the state of Louisiana, however these data are preliminary and are not consistently reported throughout this time period. That being said, the data we received from Louisiana for 2012-2015 includes the exact state of residence, and indicate a $31.5 \%$ increase in the number of abortions in Louisiana for Texas residents between 2012 and the average over 2013-2015. 
Table 1: Summary Statistics - Aggregated Annually

\begin{tabular}{|c|c|c|}
\hline & Mean & Std. Dev. \\
\hline \multicolumn{3}{|l|}{ Panel A: Abortion Data } \\
\hline Abortion rate (all ages) & 12.97 & $(6.24)$ \\
\hline Abortion rate $15-19$ & 9.01 & $(4.75)$ \\
\hline Abortion rate $20-29$ & 46.87 & $(24.69)$ \\
\hline Abortion rate $30-39$ & 19.43 & $(9.33)$ \\
\hline Abortion rate $40-44$ & 2.86 & $(1.51)$ \\
\hline \multicolumn{3}{|l|}{ Panel B: Natality Data } \\
\hline$\overline{\text { Fertility rate (all ages) }}$ & 73.2 & $(10.6)$ \\
\hline Fertility rate $15-19$ & 49.5 & $(18.2)$ \\
\hline Fertility rate $20-29$ & 240.1 & $(52.8)$ \\
\hline Fertility rate $30-39$ & 140.3 & $(22.6)$ \\
\hline Fertility rate $40-44$ & 9.73 & $(2.84)$ \\
\hline Mothers Hispanic (\%) & 0.46 & $(0.21)$ \\
\hline Mothers high school or less (\%) & 0.51 & $(0.11)$ \\
\hline Mothers unmarried (\%) & 0.41 & $(0.08)$ \\
\hline First child $(\%)$ & 0.39 & $(0.03)$ \\
\hline Second child (\%) & 0.31 & $(0.02)$ \\
\hline Third child (\%) & 0.18 & $(0.02)$ \\
\hline \multicolumn{3}{|l|}{ Panel C: Nielsen Data (store level) } \\
\hline Contraceptive expenditures (\$) & 4,401 & $(6,496)$ \\
\hline \multicolumn{3}{|l|}{ Panel D: Treatments } \\
\hline Driving dist. nearest abortion clinic (mi) & 25.9 & $(44.6)$ \\
\hline 2015 pop. with no abortion clinic in $25 \mathrm{mi}(\%)$ & 0.40 & \\
\hline 2015 pop. with no abortion clinic in 50mi (\%) & 0.26 & \\
\hline 2015 pop. with no abortion clinic in $100 \mathrm{mi}(\%)$ & 0.13 & \\
\hline Driving dist. nearest funded FP clinic (mi) & 7.8 & $(11.6)$ \\
\hline 2015 pop. with no funded FP clinic in $10 \mathrm{mi}(\%)$ & 0.23 & \\
\hline 2015 pop. with no funded FP clinic in $25 \mathrm{mi}(\%)$ & 0.13 & \\
\hline
\end{tabular}

Notes: There are 2,286 observations, except for the birth composition variables which only have 2,274 observations due to missing data. Less than half a percent are missing. For the natality data, we exclude observations from 2015 in these summary statistics as only part of the year is observed. Abortion rates and fertility rates are calculated as per 1,000 in the relevant age group (the relevant age group for the all-age rates is 15-44). In Panel D, "2015 pop. with no clinic" reports the percentage of the population that has no clinic of either type within the corresponding driving distance. All summary statistics are aggregated to the annual level (e.g., annual fertility rates) although regressions are estimated at the monthly level when possible. All countylevel means are weighted by population; the store-level means for the Nielsen data are unweighted. 
Table 2: Pre-Trends Test: $\Delta$ Past Fertility Rate (2006-2011) on $\Delta$ Future Clinic Access (2011+)

\begin{tabular}{lcccc}
\hline Panel A: Abortion Access & & & \\
& Max. $\Delta$ Dist. & $\Delta$-No Clinics & $\Delta$-No Clinics & $\Delta$-No Clinics \\
& (Jan. 2011+) & $25 \mathrm{mi}$ & $50 \mathrm{mi}$ & $100 \mathrm{mi}$ \\
\hline $\begin{array}{l}\Delta \text { Fertility Rate } \\
2006-2010\end{array}$ & 0.319 & -0.001 & -0.008 & -0.005 \\
& $(4.301)$ & $(0.001)$ & $(0.007)$ & $(0.012)$
\end{tabular}

Panel B: Family Planning Access

\begin{tabular}{lccc} 
& Max. $\Delta$ Dist. & $\Delta$-No Clinics & $\Delta$-No Clinics \\
& (Jan. 2011+) & $10 \mathrm{mi}$ & $25 \mathrm{mi}$ \\
\hline$\Delta$ Fertility Rate & -0.747 & 0.006 & -0.008 \\
$2006-2010$ & $(1.305)$ & $(0.007)$ & $(0.010)$
\end{tabular}

Notes: This table tests whether pre-treatment changes in the outcome predict subsequent changes in treatment status. The analysis is at the county level and includes 253 observations. Each estimate comes from a separate regression. The regressor in all specifications is the change in the mean annual all-age fertility rate between 2006 and 2010. The standard deviation for the regressor is 1.1, meaning that the marginal effects presented here can be roughly interpreted as the impacts of a one standard deviation increase in the regressor. The outcomes are various measures of the treatment. In the first column of each panel, the outcome is the change in driving distance between January 2011 and the maximum observed driving distance for that county post-January 2011. In the following columns, the outcomes represent whether our measures of access changed between Jan. 2011 and the end of the sample. For example, " $\Delta$-No Clinics $50 \mathrm{mi}$ " is an indicator equal to one if a county changed from having at least one clinic within 50 miles to having none. Robust standard errors are reported in parentheses. 
Table 3: Access to Abortion \& Family Planning Clinics on Number of Abortions (Poisson)

\begin{tabular}{lcccc}
\hline & $(1)$ & $(2)$ & $(3)$ & $(4)$ \\
Panel A: Abortion Access & & & & \\
\hline No Clinics 25 mi & -0.239 & -0.252 & -0.180 & -0.180 \\
& $(0.095)$ & $(0.092)$ & $(0.071)$ & $(0.071)$ \\
No Clinics 50 mi & -0.267 & -0.280 & -0.208 & -0.208 \\
& $(0.088)$ & $(0.086)$ & $(0.067)$ & $(0.067)$ \\
No Clinics 100 mi & -0.381 & -0.385 & -0.327 & -0.329 \\
& $(0.096)$ & $(0.096)$ & $(0.081)$ & $(0.083)$ \\
Panel B: Family Planning Access & & & & \\
\hline No Clinics 10 mi & -0.007 & -0.006 & 0.019 & 0.051 \\
& $(0.028)$ & $(0.028)$ & $(0.030)$ & $(0.024)$ \\
No Clinics 25 mi & -0.041 & -0.041 & -0.020 & 0.019 \\
& $(0.038)$ & $(0.039)$ & $(0.037)$ & $(0.029)$ \\
\hline Economic Controls & - & $\mathrm{X}$ & $\mathrm{X}$ & $\mathrm{X}$ \\
Demographic Controls & - & - & $\mathrm{X}$ & $\mathrm{X}$ \\
Access Controls & - & - & - & $\mathrm{X}$ \\
Observations & 2,277 & 2,277 & 2,277 & 2,277 \\
\hline
\end{tabular}

Notes: The analysis is at the county-year level, and the coefficients represent estimates from a fixed-effects Poisson model with the number of abortions in each category as the outcome. The exposure variable is the population of females 15-44 years old. Each estimated coefficient comes from a separate regression, and the treatment variables of interest are dummy variables indicating that there were no clinics (abortion or publicly-funded family planning) in the relevant driving distance. All regressions include county and year fixed effects. Economic controls are the unemployment rate and log per capita income; demographic controls are age- and race-specific populations; access controls include the distance to the nearest family planning clinic in the abortion regressions, and vice-versa. Standard errors are reported in parentheses and are clustered at the county level. 
Table 4: Access to Abortion \& Family Planning Clinics on Number of Births (Poisson)

\begin{tabular}{lcccc}
\hline & $(1)$ & $(2)$ & $(3)$ & $(4)$ \\
Panel A: Abortion Access & & & & \\
\hline No Clinics 25 mi & 0.014 & 0.015 & 0.018 & 0.018 \\
& $(0.014)$ & $(0.013)$ & $(0.011)$ & $(0.010)$ \\
No Clinics 50 mi & 0.030 & 0.030 & 0.030 & 0.031 \\
& $(0.010)$ & $(0.009)$ & $(0.009)$ & $(0.009)$ \\
No Clinics 100 mi & 0.019 & 0.017 & 0.017 & 0.019 \\
& $(0.012)$ & $(0.010)$ & $(0.011)$ & $(0.010)$ \\
Panel B: Family Planning Access & & & & \\
\hline No Clinics 10 mi & 0.002 & -0.000 & -0.011 & -0.014 \\
& $(0.013)$ & $(0.011)$ & $(0.008)$ & $(0.007)$ \\
No Clinics 25 mi & 0.021 & 0.017 & 0.004 & 0.002 \\
& $(0.008)$ & $(0.009)$ & $(0.008)$ & $(0.008)$ \\
\hline Economic Controls & - & $\mathrm{X}$ & $\mathrm{X}$ & $\mathrm{X}$ \\
Demographic Controls & - & - & $\mathrm{X}$ & $\mathrm{X}$ \\
Access Controls & - & - & - & $\mathrm{X}$ \\
Observations & 28,589 & 28,589 & 28,589 & 28,589 \\
\hline
\end{tabular}

Notes: The analysis is at the county-year-month level, and the coefficients represent estimates from a fixed-effects Poisson model with the number of births in each category as the outcome. The exposure variable is the population of females 15-44 years old. Each estimated coefficient comes from a separate regression, and the treatment variables of interest are dummy variables indicating that there were no clinics (abortion or publicly-funded family planning) in the relevant driving distance. All regressions include county and yearby-month fixed effects. Economic controls are the unemployment rate and log per capita income; demographic controls are age- and race-specific populations; access controls include the distance to the nearest family planning clinic in the abortion regressions, and vice-versa. Standard errors are reported in parentheses and are clustered at the county level. 
Table 5: Impacts of Lagged Family Planning Access on Births (Poisson)

\begin{tabular}{lcccc}
\hline & $(1)$ & $(2)$ & $(3)$ & $(4)$ \\
Panel A: No Controls & & & & \\
\hline No Clinics 25 mi (t=0) & 0.021 & 0.007 & 0.009 & 0.005 \\
& $(0.008)$ & $(0.007)$ & $(0.008)$ & $(0.008)$ \\
No Clinics 25 mi (t-12) & - & 0.018 & 0.013 & 0.013 \\
& & $(0.007)$ & $(0.006)$ & $(0.007)$ \\
No Clinics 25 mi (t-24) & - & - & 0.002 & 0.002 \\
& & & $(0.007)$ & $(0.007)$ \\
No Clinics 25 mi (t-36) & - & - & - & 0.000 \\
& & & & $(0.009)$ \\
Panel B: All Controls & & & & \\
\hline No Clinics 25 mi (t=0) & 0.002 & -0.008 & -0.004 & -0.008 \\
& $(0.008)$ & $(0.008)$ & $(0.009)$ & $(0.009)$ \\
No Clinics 25 mi (t-12) & - & 0.015 & 0.013 & 0.013 \\
& & $(0.006)$ & $(0.006)$ & $(0.006)$ \\
No Clinics 25 mi (t-24) & - & - & -0.002 & 0.000 \\
& & & $(0.007)$ & $(0.008)$ \\
No Clinics 25 mi (t-36) & - & - & - & -0.005 \\
Observations & & & & $(0.008)$ \\
\hline
\end{tabular}

Notes: The analysis is at the county-year-month level, and the coefficients represent estimates from a fixed-effects Poisson model with the number of births in each category as the outcome. The exposure variable is the population of females 15-44 years old. Within each panel, each column is a separate regression, and the treatment variables of interest are dummy variables indicating that there were no publicly-funded family planning clinics within 25 miles driving distance at the time of conception ( $\mathrm{t}=0$ ), a year prior to conception ( $\mathrm{t}-12)$, and so on. All regressions include county and year-by-month fixed effects. Panel A includes no county-level time-varying controls, and Panel B includes economic controls, demographic controls and access controls as described in Table 4. Sample sizes vary due to the lagged measures of family planning access. Standard errors are reported in parentheses and are clustered at the county level. 
Table 6: Access to Abortion \& Family Planning Clinics on IHS(Contraceptive Expenditures)

\begin{tabular}{lcccc}
\hline Panel A: Abortion Access & $(1)$ & $(2)$ & $(3)$ & $(4)$ \\
\hline No Clinics 25 mi & & & & \\
No Clinics 50 mi & 0.075 & 0.054 & 0.019 & 0.017 \\
& $(0.029)$ & $(0.025)$ & $(0.027)$ & $(0.027)$ \\
No Clinics 100 mi & 0.110 & 0.076 & 0.043 & 0.041 \\
& $(0.033)$ & $(0.031)$ & $(0.030)$ & $(0.030)$ \\
Observations & 0.128 & 0.081 & 0.050 & 0.045 \\
Panel B: Family Planning Access & & & & \\
\hline No Clinics 25 mi (t=0) & $0.033)$ & $(0.023)$ & $(0.026)$ & $(0.027)$ \\
& 233,392 & 233,392 & 233,392 & 233,392 \\
No Clinics 25 mi (t-12) & $(0.039)$ & $(0.037)$ & $(0.038)$ & $(0.039)$ \\
& 0.112 & 0.100 & 0.083 & 0.080 \\
Observations & $(0.042)$ & $(0.040)$ & $(0.041)$ & $(0.041)$ \\
\hline Economic Controls & 231,015 & 231,015 & 231,015 & 231,015 \\
Demographic Controls & - & $\mathrm{X}$ & $\mathrm{X}$ & $\mathrm{X}$ \\
Access Controls & - & - & $\mathrm{X}$ & $\mathrm{X}$ \\
\hline
\end{tabular}

Notes: The analysis is at the county-year-month level, and the coefficients represent estimates from an OLS model with the inverse hyperbolic sine of expenditures on contraceptives as the outcome. Regressions are weighted by average total expenditures on health and beauty products to account for a high degree of variation in store size. In Panel A, each estimate comes from a separate regression; in Panel B, each column is a separate regression. The treatment variables of interest are dummy variables indicating that there were no clinics (abortion or publiclyfunded family planning) in the relevant driving distance. All regressions include store and year-by-month fixed effects. Economic controls are the unemployment rate and log per capita income; demographic controls are age- and race-specific populations; access controls include the distance to the nearest family planning clinic in the abortion regressions, and vice-versa. Sample sizes vary across panels due to the lagged measure of family planning access. Standard errors are reported in parentheses and are clustered at the county level. 